SGP-TR-172

\title{
Relative Permeability of Fractured Rock
}

\author{
Mark D. Habana
}

June 2002

Financial support was provided through the

Stanford Geothermal Program under

Department of Energy Grant No. DE-FG07-99ID13763, and by the Department of Petroleum Engineering,

Stanford University

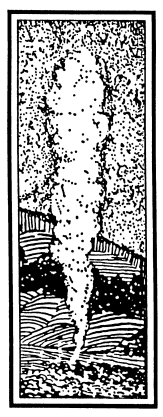

Stanford Geothermal Program

Interdisciplinary Research in

Engineering and Earth Sciences

STANFORD UNIVERSITY

Stanford, California 



\section{Abstract}

Contemporary understanding of multiphase flow through fractures is limited. Different studies using synthetic fractures and various fluids have yielded different relative permeability-saturation relations. This study aimed to extend the understanding of multiphase flow by conducting nitrogen-water relative permeability experiments on a naturally-fractured rock from The Geysers geothermal field.

The steady-state approach was used. However, steady state was achieved only at the endpoint saturations. Several difficulties were encountered that are attributed to phase interference and changes in fracture aperture and surface roughness, along with fracture propagation/initiation.

Absolute permeabilities were determined using nitrogen and water. The permeability values obtained change with the number of load cycles. Determining the absolute permeability of a core is especially important in a fractured rock. The rock may change as asperities are destroyed and fractures propagate or strain harden as the net stresses vary.

Pressure spikes occurred in water absolute permeability experiments. Conceptual models of an elastic fracture network can explain the pressure spike behavior.

At the endpoint saturations the water relative permeabilities obtained are much less than the nitrogen gas relative permeabilities.

Saturations were determined by weighing and by resistivity calculations. The resistivitysaturation relationship developed for the core gave saturation values that differ by $\pm 5 \%$ from the value determined by weighing.

Further work is required to complete the relative permeability curve. The steady-state experimental approach encountered difficulties due to phase interference and fracture changes. Steady state may not be reached until an impractical length of time. Thus, unsteady-state methods should be pursued. In unsteady-state experiments the challenge will be in quantifying rock fracture changes in addition to fluid flow changes. 



\section{Acknowledgments}

This research was supported by the US Department of Energy under contract DE-FG0799ID13763.

My sincerest gratitude goes to Roland N. Horne for his patience, understanding, guidance, and ready support. Kewen Li, Chih-Ying Chen, and Charles E. Campbell were invaluable in completing the laboratory work.

Much motivation was provided by my family: Pauletta, Carlos, Paulette, Eisen, Lolo, Lola, Nanay, and Tatay.

This work is dedicated to Therese for her patient love and encouragement. Above all, this work is offered to God for His greater glory. 



\section{Contents}

Acknowledgments

2.1 Darcy's Law and Slip Factors .......................................................................... 2

2.2 Relative Permeability Curves .......................................................................... 3

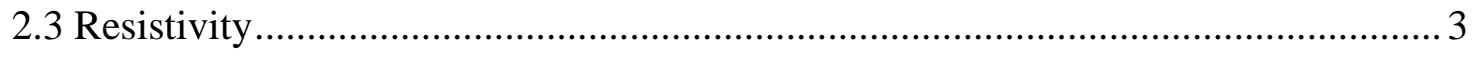

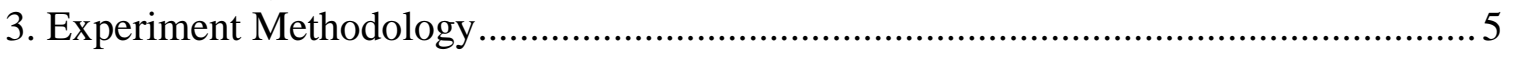

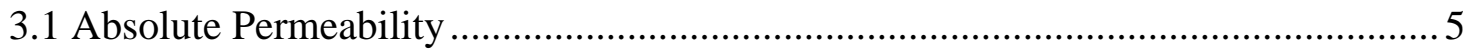

3.1.1 Nitrogen and Helium Experiments ............................................................ 5

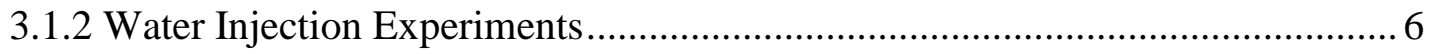

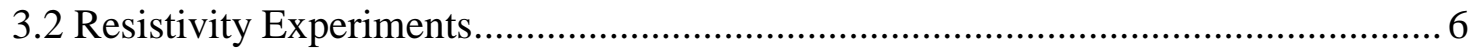

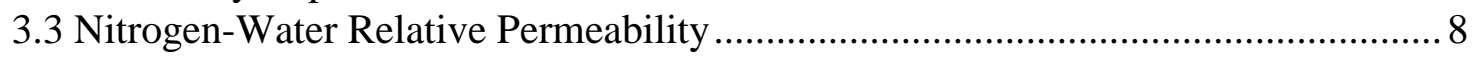

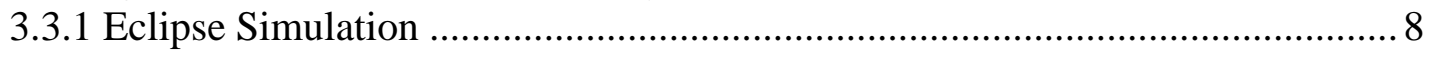

3.3.2 Relative Permeability at Endpoint Saturations ....................................... 8

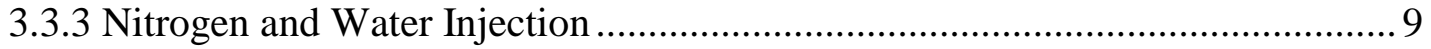

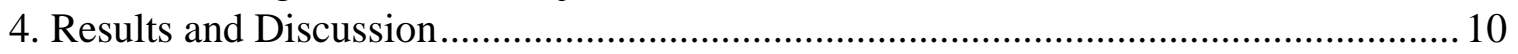

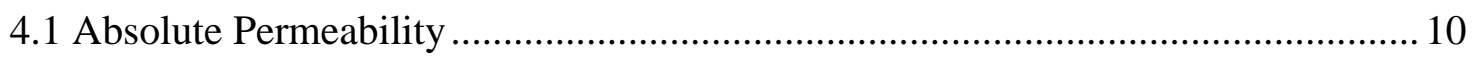

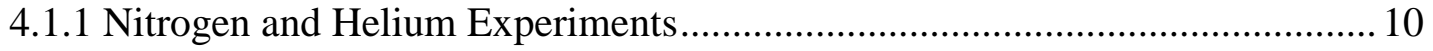

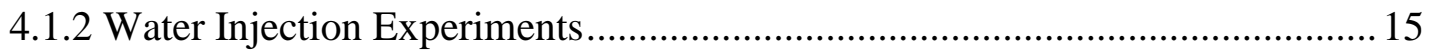

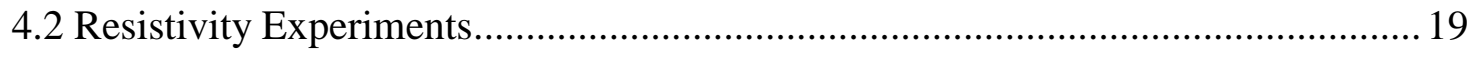

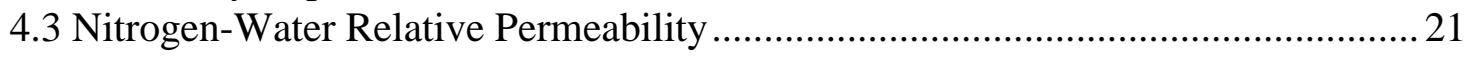

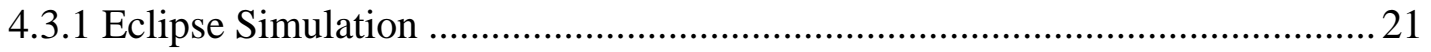

4.3.2 Relative Permeability at Endpoint Saturations.......................................... 24

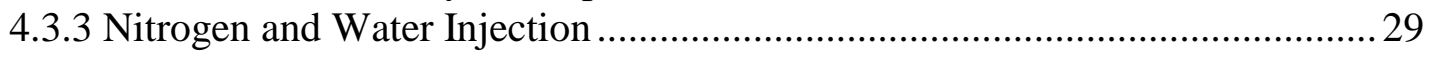

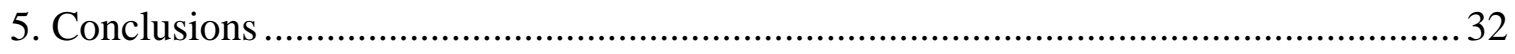

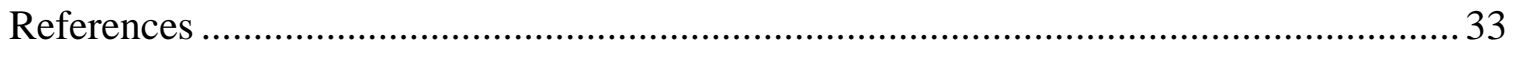

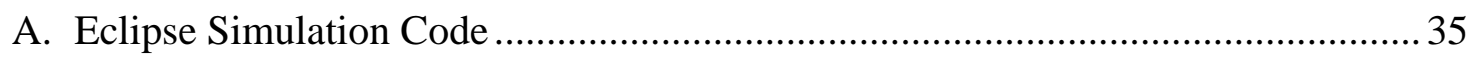

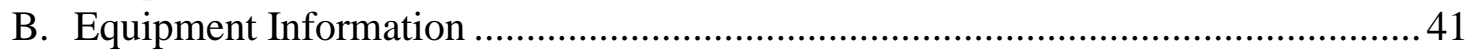




\section{List of Tables}

Table 4.1: Absolute permeability and slip factor values from nitrogen experiments. $\quad 14$

Table 4.2: Absolute permeability values from water injection experiments. 18

Table 4.3: Irreducible water saturation. 20

Table 4.4: Water saturation at irreducible nitrogen gas saturation. 21

Table 4.5: Nitrogen gas relative permeability from Experiment 1. 27

Table 4.6: Nitrogen gas relative permeability from Experiment 2. 27

Table 4.7: Water relative permeability from Experiment $1 . \quad 27$

Table 4.8: Water relative permeability from Experiment 2. 27 



\section{List of Figures}

Figure 3.1: Apparatus for flow measurement in geothermal rock. 5

Figure 3.2 Apparatus for resistivity experiments.

Figure 3.3: Apparatus for determining resistivity-saturation correlation in geothermal rock. 7

Figure 3.4: Apparatus for nitrogen-water relative permeability experiment. $\quad 8$

Figure 4.1: Results of nitrogen and helium permeability as a function of pressure. 10

Figure 4.2: Absolute permeability results from nitrogen experiments. $\quad 11$

Figure 4.3: Results of helium and nitrogen permeability as a function of pressure.

$\begin{array}{ll}\text { From experiment } \mathrm{C} \text {. } & 11\end{array}$

Figure 4.4: Results of helium and nitrogen permeability as a function of pressure.

$\begin{array}{ll}\text { From experiment F. } & 12\end{array}$

Figure 4.5: Nitrogen experiment results for the 2" diameter core. 13

Figure 4.6: Schematic of fracture surface.

Figure 4.7: Pressure at inlet during water injection. Constant water flowrate at $10 \mathrm{ml} / \mathrm{min}$. 15

Figure 4.8: Pressure at inlet during water injection. Constant water flowrate at $14 \mathrm{ml} / \mathrm{min}$. 16

Figure 4.9: Continuous vs discontinuous propagation. From Renshaw and Pollard. 17

Figure 4.10: Pressure at inlet during water injection. Constant water flowrate at $2 \mathrm{ml} / \mathrm{min}$. 17

Figure 4.11: Pressure at inlet during water injection. Constant water flowrate at $0.1 \mathrm{ml} / \mathrm{min}$. 18

Figure 4.12: $R_{\text {index }}$ versus water saturation for homogeneous rock. $\quad 19$

Figure 4.14: Resistance versus water saturation for 2" diameter core from The Geysers. 20

Figure 4.15: Saturation map for imbibition with horizontal fracture. 22

Figure 4.16: Saturation map for imbibition with short horizontal fracture. 23

Figure 4.17: Saturation map for imbibition with inclined fracture 23

Figure 4.18: Pressure at inlet during water injection at constant water flowrate of

$0.05 \mathrm{ml} / \mathrm{min}$. From Experiment 1.

Figure 4.19: Pressure and flowrate at inlet during gas injection. From Experiment 1.

Figure 4.20: Pressure at inlet during water injection at constant water flowrate of

$0.5 \mathrm{ml} / \mathrm{min}$. From Experiment 2 . 26

Figure 4.21: Pressure and flowrate at inlet during gas injection. From Experiment 2.

Figure 4.22: Simulation of effect of stress on relative permeabilities.

$\begin{array}{ll}\text { From Pyrak-Nolte et al. } & 28\end{array}$

Figure 4.23: Pressure at inlet for constant flowrate nitrogen-water relative permeability $\begin{array}{ll}\text { experiment. } & 30\end{array}$

Figure 4.24: Pressure at inlet for nitrogen-water relative permeability experiment 30

Figure 4.25: Nitrogen inlet flowrate for nitrogen-water relative permeability experiment. 31 



\section{Chapter 1}

\section{Introduction}

Relative permeability is one of the most uncertain terms in equations of multiphase fluid flow through porous and fractured media. Such a basic parameter must be well understood to have confidence in reservoir simulations and other models of fractured media that are based on these equations.

Much work has been done dealing with flow properties in nonfractured porous media. Increased understanding of flow behavior in fractures will allow more realistic models. This work aimed to determine nitrogen-water relative permeability relations for a fractured geothermal rock from The Geysers.

Various works on flow through fractures have shown different kinds of relative permeability behavior. Experimental studies by Persoff and Pruess (1995) resulted in curves that can not be classified either as Corey type or as linear (X-curve) type. Fourar et al. (1993) suggested that multiphase interaction in a fracture is a function of flow velocity and, therefore, relative permeability is not the appropriate way to describe multiphase flow in fractures.

Past experiments have used synthetic fabricated fractures and/or gas-water or oil-water as fluids. This experimental study used a real fractured rock core from The Geysers geothermal field to study nitrogen-water relative permeability.

Understanding nitrogen-water relative permeability through fractures will provide valuable information prior to the next challenge: steam-water relative permeability. 


\section{Chapter 2}

\section{Theoretical Background}

\subsection{Darcy's Law and Slip Factors}

One-dimensional flow through porous media is described by Darcy's law.

$$
q=\frac{k_{a b s} k_{r} A}{\mu} \frac{\Delta p}{\Delta x}
$$

where $q$ is the volumetric flowrate

$k$ is the absolute permeability

$k_{r}$ is the relative permeability

$A$ is the cross sectional area of flow

$\mu$ is the fluid viscosity

$\Delta p / \Delta x$ is the pressure gradient

For isothermal flow of an ideal gas Darcy's law is modified as Equation (2-2).

$$
q_{\text {mean }}=\frac{k_{a b s} k_{r} A}{\mu} \frac{\Delta p}{\Delta x}
$$

where $q_{\text {mean }}$ is the volume flowrate at the mean pressure

The Klinkenberg effect is observed for gas flows wherein the absolute permeability calculated using Darcy's equation is greater than the real absolute permeability. The slip factor is introduced to correct for this difference.

$$
k_{a b s}=\frac{k_{g a s}}{\left(1-\frac{b}{p_{a v e}}\right)}
$$

where $b$ is the slip factor

$p_{a v e}$ is the average of the inlet and outlet pressures

$k_{\text {gas }}$ is the uncorrected permeability

$k_{a b s}$ is the absolute permeability 
The value of the slip factor is obtained by plotting the gas permeability values versus the reciprocal of different mean pressures. Extrapolating the curve to the y-axis gives the correct value of absolute permeability. Dividing the slope by the y-intercept of the equation of the extrapolated line gives the slip factor.

\subsection{Relative Permeability Curves}

Corey curves are observed often in homogeneous porous media while X-curves are typically assumed for fracture flows.

The Corey and X-curves are modeled by the equations below.

Corey Curves:

$$
\begin{array}{ll}
k_{r l}=S^{* 4} & \left(S^{*}<1\right) \\
k_{r l}=\left(1-S^{*}\right)^{2}\left(1-S^{* 2}\right) & \left(S^{*}<1\right) \\
S^{*}=\frac{\left(S-S_{l r}\right)}{\left(S_{g r}-S_{l r}\right)} &
\end{array}
$$

X-curves:

$$
\begin{array}{ll}
k_{r l}=S^{*} & \left(S^{*}<1\right) \\
k_{r l}=\left(1-S^{*}\right) & \left(S^{*}<1\right) \\
S^{*}=\frac{\left(S-S_{l r}\right)}{\left(S_{g r}-S_{l r}\right)} &
\end{array}
$$

where $k_{r l}$ is the relative permeability of the liquid and $k_{r g}$ is the relative permeability of the gas. $S_{l r}$ is the irreducible water saturation and $S_{g r}$ is the water saturation at irreducible nitrogen gas saturation.

\subsection{Resistivity}

Experiments by Archie(1942) showed a relationship between resistivity and saturation. Resistivity is the reciprocal of conductivity, or the ability of a material to allow flow of current. 


$$
\rho=r\left(\frac{A}{L}\right)
$$

where $r$ is resistance

$A$ is area

$L$ is length

$\rho$ is resistivity

Archie's equation relates the resistivity index to the water saturation.

$$
\begin{gathered}
R_{\text {index }}=S_{w}^{-2} \\
R_{\text {index }}=\rho_{t} / \rho_{o}
\end{gathered}
$$

where $R_{\text {index }}$ is the resistivity index

$\rho_{t}$ is the resistivity of the core with less than $100 \%$ water saturation $\rho_{o}$ is the resistivity of the core at $100 \%$ water saturation

Thus, knowing $R_{\text {index }}$ the water saturation, $S_{w}$, can be computed. 


\section{Chapter 3}

\section{Experiment Methodology}

Several preliminary experiments and flow simulations were conducted prior to the nitrogen-water relative permeability experiments. These were done to determine issues involved in conducting the experiment on a fractured rock.

\subsection{Absolute Permeability}

\subsubsection{Nitrogen and Helium Experiments}

The core sample was obtained from a depth of $1409.3 \mathrm{~m}$ at The Geysers geothermal field. The core is $6.91 \mathrm{~cm}$ in diameter and $4.70 \mathrm{~cm}$ in length.

The rock permeability was measured using nitrogen and helium gas at room temperature. Since gas permeability is a function of pressure, as described by Equation 2-3, the flow measurements were conducted at a series of different mean pressures.

At different confining pressures nitrogen was flowed through the core. Confining pressure from 500 to 850 psig was applied by injecting nitrogen around the heat shrink tubing inside the core holder. To apply a confining pressure of 1150 psig water was used in place of nitrogen.

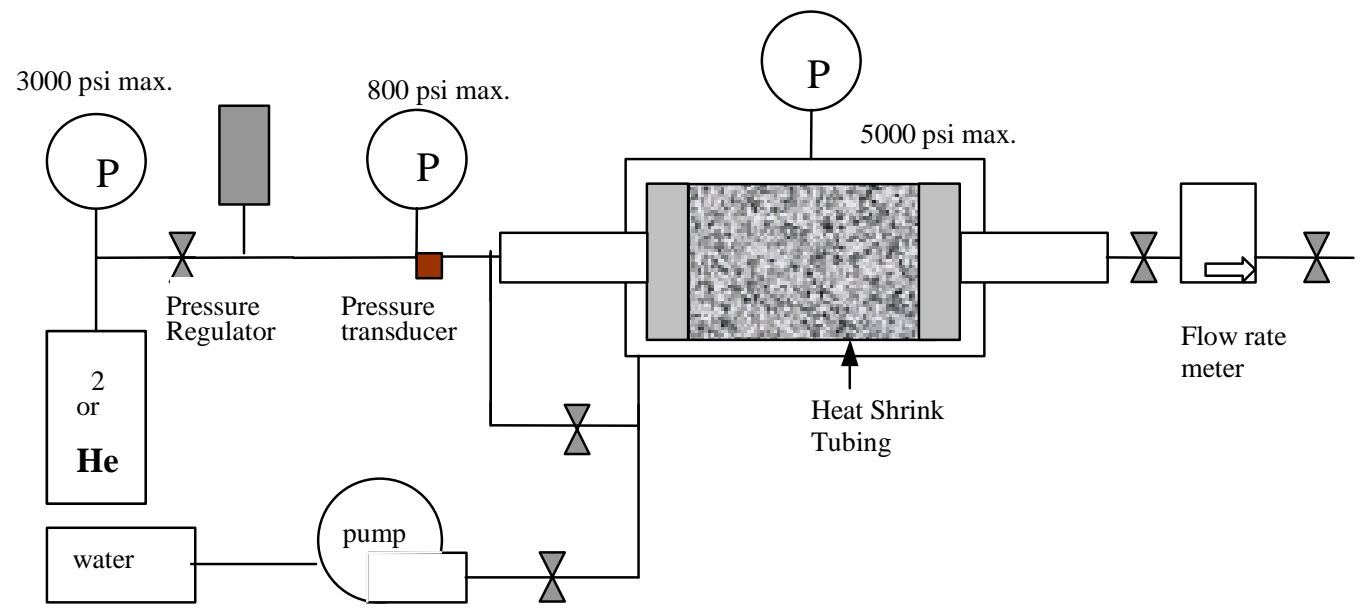

Figure 3.1: Apparatus for flow measurement in geothermal rock. 
A pressure gauge and a pressure transducer connected to a digital display measured pressure at the inlet. The pressure at the outlet was taken to be $1 \mathrm{~atm}$. The flow rate at the outlet was measured using a Matheson flow rate meter and controller (Model 8272MF2000). The flow rate transducer calibration equation used was that determined by Kewen Li when he used the device in his experiments on slip factors (Oct-Dec 1999 Quarterly Report).

Nitrogen absolute permeability experiments were also conducted on another core. This core, with a diameter of $5.08 \mathrm{~cm}$ (2") and a length of $4.445 \mathrm{~cm}$, was cut from The Geysers geothermal rock obtained at a depth 1450 meters. This 2 " diameter core was made so a standard rubber sleeve could be used instead of the heat shrink tubing.

Three nitrogen experiments were completed for the 2" diameter core. The first one was conducted after drying the newly cut core and the second after performing several nitrogen-water relative permeability experiment runs.

The third nitrogen experiment was done under constant net stress. The net stress was controlled by reducing (or increasing) the confining pressure by the same amount as the decrease (or increase) of the inlet and outlet pressures. The pressure difference between the inlet and outlet was maintained constant.

\subsubsection{Water Injection Experiments}

Four water injection experiments were conducted on the 2" diameter core. The first was conducted after vacuuming the core; after the first nitrogen absolute permeability experiment. The flowrate was maintained constant at $10 \mathrm{ml} / \mathrm{min}$. Steady state was deemed achieved when the pressure at the inlet was relatively constant. The outlet pressure was maintained at atmospheric pressure.

The other three water injection experiment runs were done after the second nitrogen absolute permeability experiment. Different water flowrates were used in the three runs: $14 \mathrm{ml} / \mathrm{min}, 10 \mathrm{ml} / \mathrm{min}$, and $0.1 \mathrm{ml} / \mathrm{min}$.

The water pump maximum outlet pressure was set to $800 \mathrm{psig}$. This was done to prevent pressure in the core from exceeding the confining pressure of $850 \mathrm{psig}$.

\subsection{Resistivity Experiments}

Two resistivity experiments were done using a disc-shaped homogeneous rock. The same experiment was done also using a heterogeneous rock. The apparatus is shown in Figure 3.2 . 


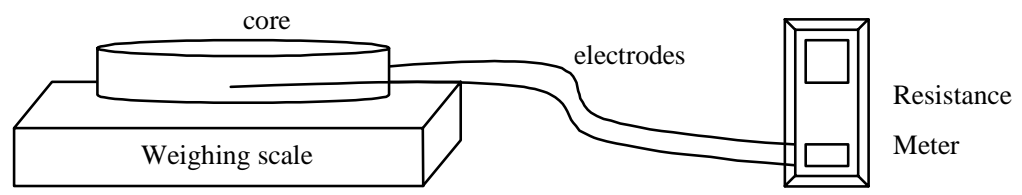

Figure 3.2 Apparatus for resistivity experiments.

The core was saturated fully with water and then allowed to dry on a weighing scale. Resistance measurements were measured for every 1 gram decrease in mass of the saturated core. Resistivity and resistivity indices were calculated for each resistance reading by using Equation 2-10, Equation 2-11 and Equation 2-12.

To determine the resistivity-saturation correlation for the 2" diameter Geysers core the apparatus shown in Figure 3.3 was used.

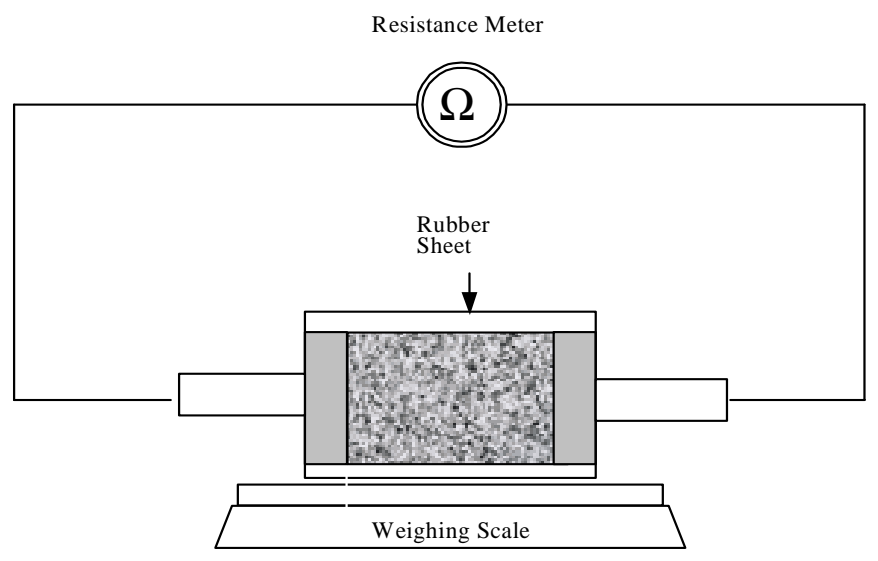

Figure 3.3: Apparatus for determining resistivity-saturation correlation in geothermal rock.

The core was fully saturated with water and then wrapped with rubber sheet, with the two metal plates attached on both ends of the core. The core was then allowed to dry on a weighing scale. Resistance measurements were measured as the mass of the saturated core decreased.

The resistance meter has a maximum resistance reading of $40 \mathrm{M} \Omega$. To be able to measure resistances higher than $40 \mathrm{M} \Omega$ several resistors and rheostats in series connection were assembled. Connecting these resistors to the core in parallel caused the overall resistance to decrease below $40 \mathrm{M} \Omega$. The core resistance was then computed using the basic equation for parallel resistances. 


\subsection{Nitrogen-Water Relative Permeability}

\subsubsection{Eclipse Simulation}

Flow simulations were done to determine whether uniform saturation could be achieved in the core and to estimate the amount of time required to achieve steady state.

The cylindrical core was modeled as a rectangular reservoir. Grid block parameter values were $4.3 \%$ for porosity and $0.5 \mathrm{md}$ for permeability. The Eclipse simulation code used is listed in Appendix A.

\subsubsection{Relative Permeability at Endpoint Saturations}

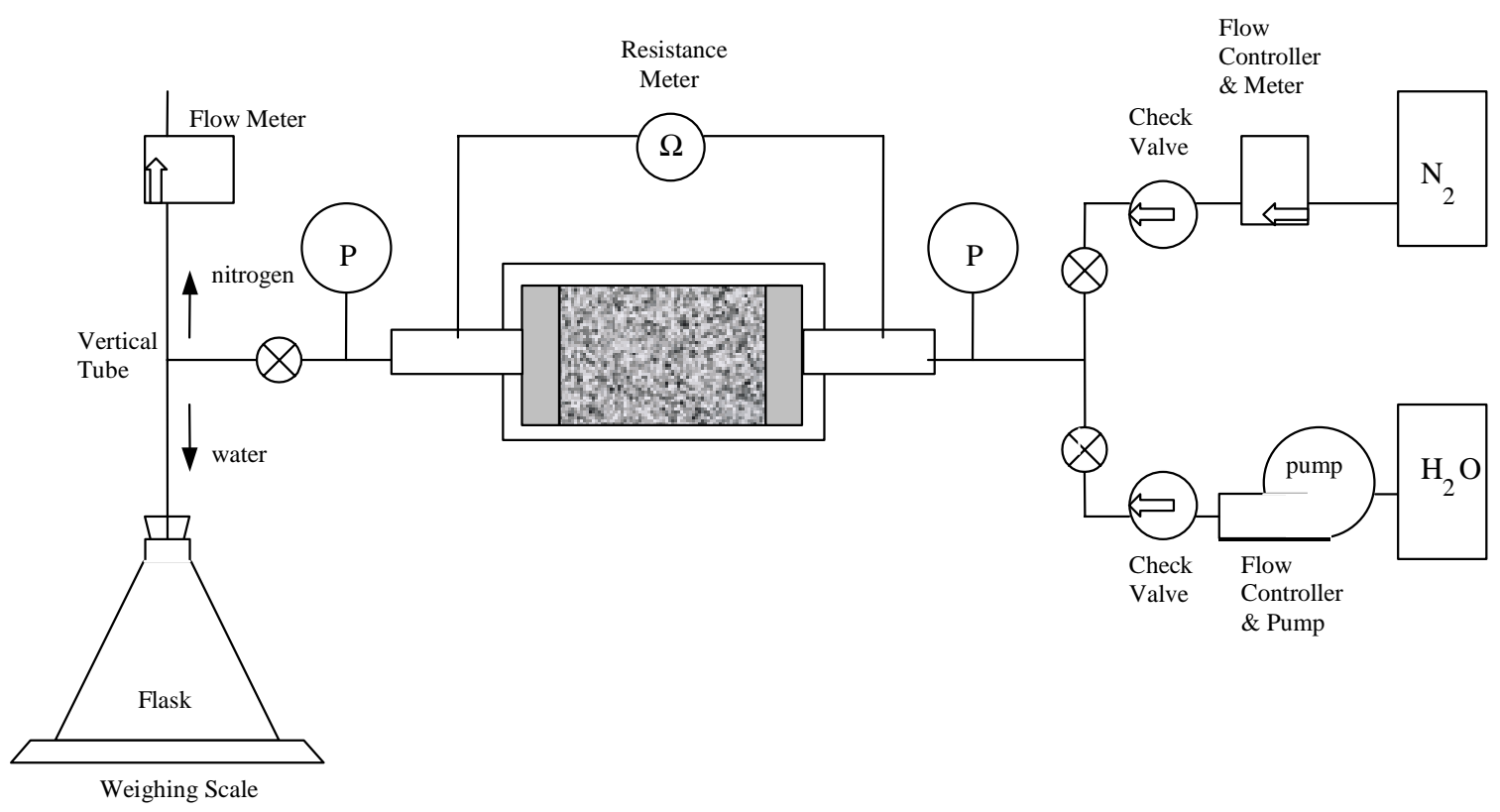

Figure 3.4: Apparatus for nitrogen-water relative permeability experiment.

The experiments had inlet flow controls of constant nitrogen gas pressure and constant water flowrate. The data acquisition system was automated using a PCI-6024E board and an SCB-68 shielded connector block; both manufactured by National Instruments. Resistance measurements were taken at the end of the experiment runs for use in determining the water saturation. The metal stems of the core endplates were covered with Torlon plastic to isolate the core electrically from the core holder.

During relative permeability experiments at irreducible water saturation the nitrogen gas injected was made to pass through a cylinder containing water. This was done to saturate the gas with water. 
Two sets of endpoint saturation relative permeability experiments were completed. Each set includes an experiment at irreducible water saturation and another experiment at irreducible nitrogen saturation.

\subsubsection{Nitrogen and Water Injection}

Several nitrogen-water relative permeability experiment runs were done. Initially, the inlet flow control was at constant flowrate for both nitrogen and water. Later experiments controlled the inlet pressure of nitrogen and the inlet flowrate of water.

Five constant flowrate nitrogen-water relative permeability experiments were completed. Difficulties in achieving steady state were encountered and, thus, the experiment was changed to constant nitrogen gas pressure and constant water flowrate. 


\section{Chapter 4}

\section{Results and Discussion}

\subsection{Absolute Permeability}

\subsubsection{Nitrogen and Helium Experiments}

Results of the nitrogen experiments on the $6.91 \mathrm{~cm}$ diameter core are shown in Figure 4.1. The intersection of the extrapolated lines with the vertical axis in the plot of permeability $(k)$ versus the reciprocal of the mean pressure $\left(1 / p_{\text {ave }}\right)$ is taken to be the absolute permeability of the rock. The values of permeability range between 0.22 and $0.38 \mathrm{md}$.

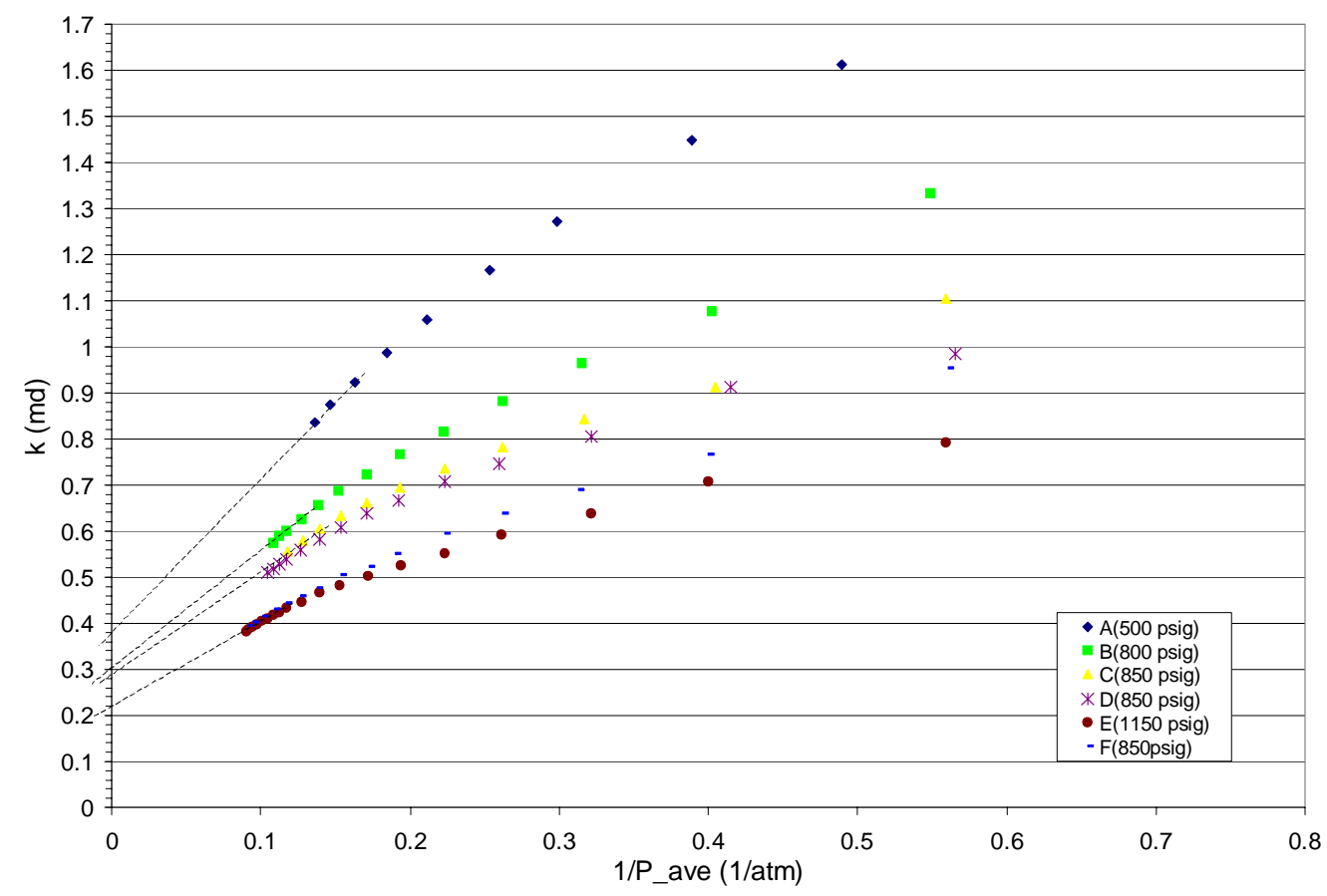

Figure 4.1: Results of nitrogen and helium permeability as a function of pressure.

It was observed that for the nitrogen experiments the permeability values decrease with increasing confining pressure. This can be attributed to the increase in net stress on the rock fractures as the confining pressure is increased. The increased net stress reduces the fracture aperture and, consequently, reduces the permeability. 
There is a linear relationship between confining pressure and the absolute permeabilities obtained by extrapolation. This is shown in Figure 4.2.

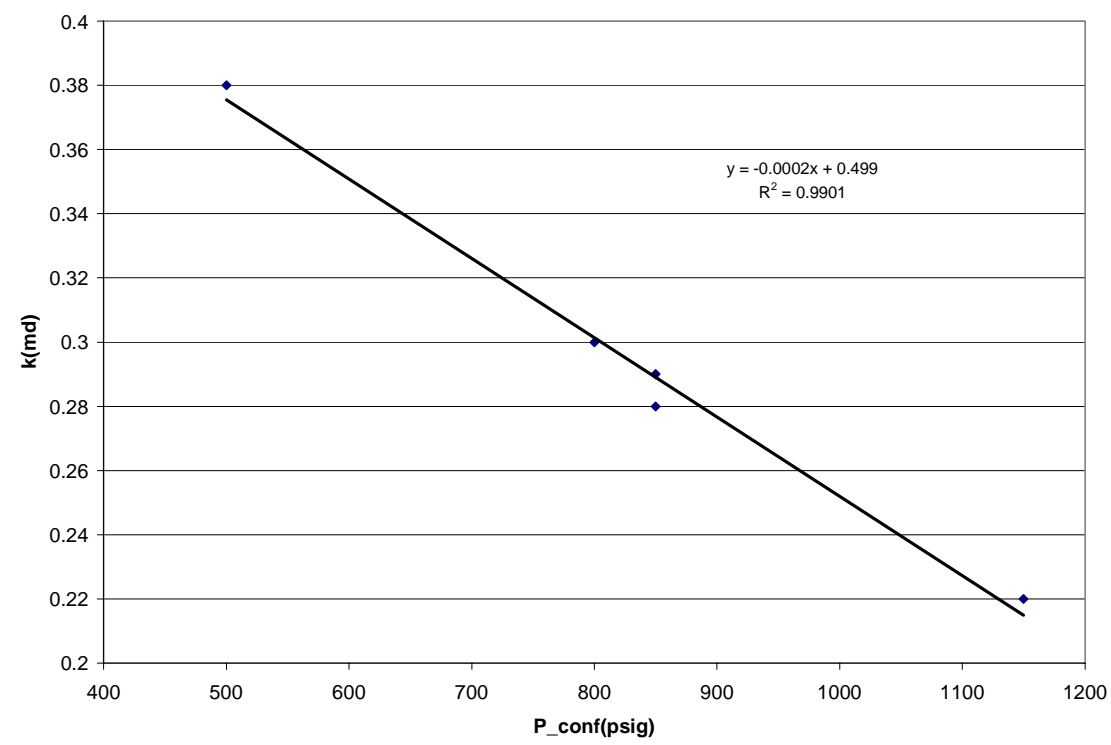

Figure 4.2: Absolute permeability results from nitrogen experiments.

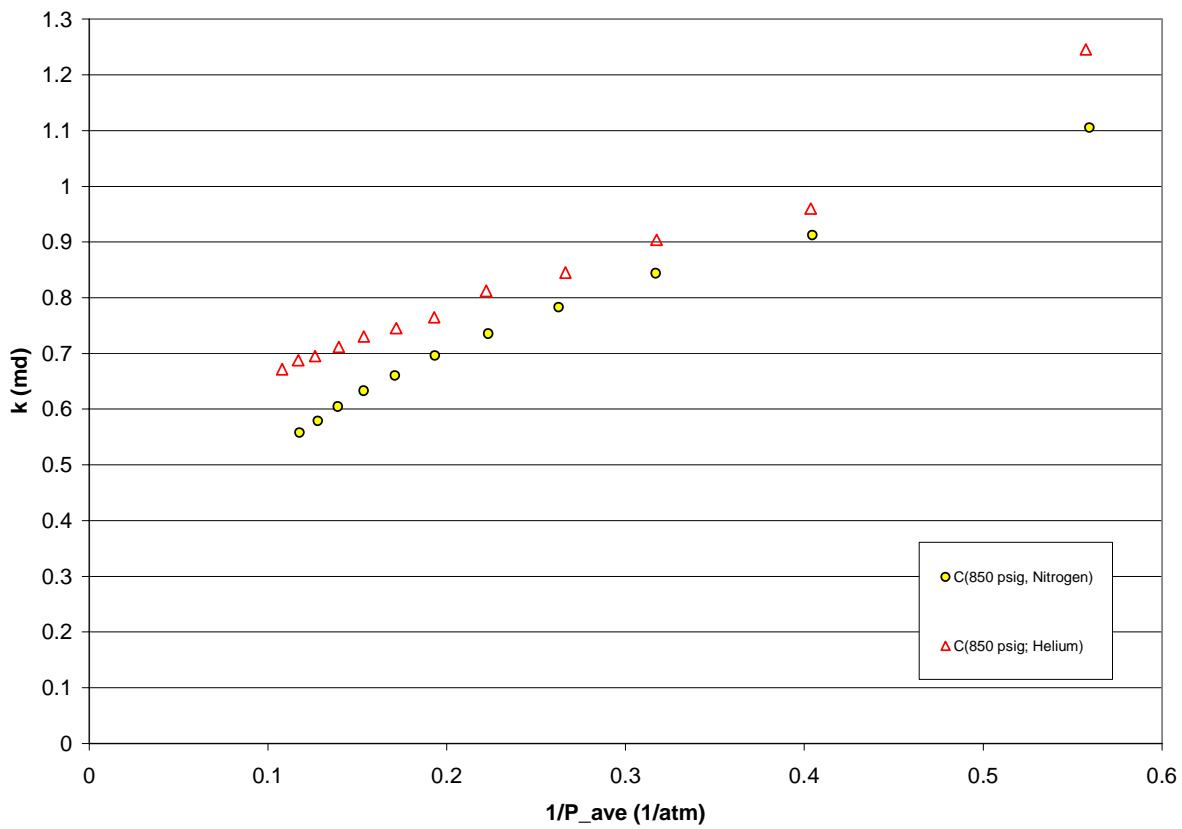

Figure 4.3: Results of helium and nitrogen permeability as a function of pressure. From experiment $\mathrm{C}$.

Figure 4.3 and 4.4 show two helium experiment results compared to the two nitrogen experiments preceding each helium experiment. All four flow experiments were done at a 
confining pressure of 850 psig. For the helium experiment the permeabilities obtained are higher than the values from the nitrogen experiments. Also, the slope for the helium experiment is lower than that for nitrogen at high confining pressures. This is not as expected. The slope for helium should be much steeper than that for nitrogen considering the difference in viscosities and molecular weights of the two fluids.

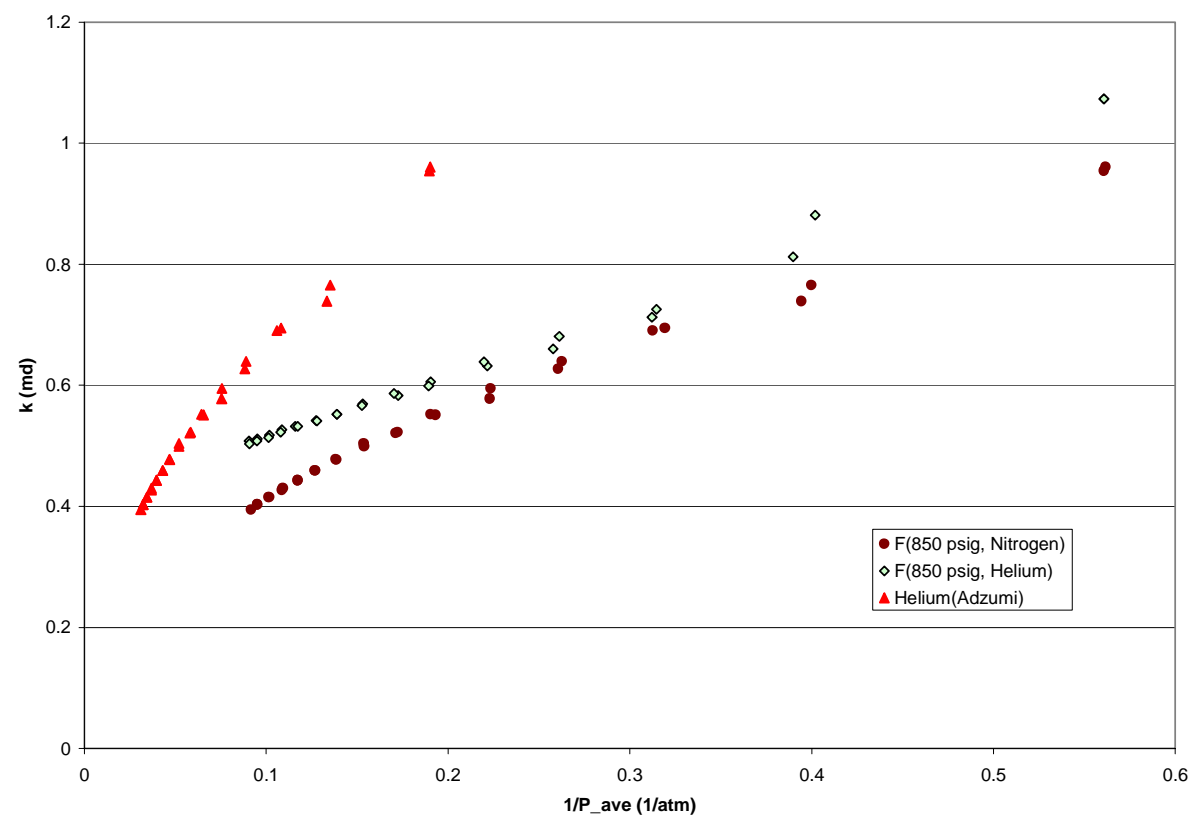

Figure 4.4: Calculated helium permeability values using Adzumi's equation and results of helium and nitrogen permeability as a function of pressure. From experiment $\mathrm{F}$.

Assuming that the nitrogen data in Figure 4.4 is correct we can calculate the helium permeabilities for a porous media using Adzumi's equation, Equation 4-1.

$$
\frac{p_{2}}{p_{1}}=\left(\frac{\mu_{2}}{\mu_{1}}\right) \sqrt{T_{2} M_{1} / T_{1} M_{2}}
$$

$$
k_{g}\left(\text { gas } 1 \text { at } p_{1} \text { and } T_{1}\right)=k_{g}\left(\text { gas } 2 \text { at } p_{2} \text { and } T_{2}\right)
$$

where $p$ is pressure

$T$ is temperature

$\mu$ is viscosity

subscripts 1 and 2 determine the gas

The calculated helium permeability values are shown as triangles in Figure 4.4. This implies that the permeability for a porous core is higher than that for a fractured core. Viscosity and molecular weight effects were investigated but were not able to provide an explanation for the discrepancies observed. It was found that helium was at supercritical conditions during the entire experiment. The critical pressure of helium is $2.2449 \mathrm{~atm}$ and 
its critical temperature is $-267.95{ }^{\circ} \mathrm{C}$. This critical pressure corresponds to a value of the reciprocal of mean pressure of 0.616 . Ordinary flow equations, therefore, do not apply to the helium data obtained. Nitrogen, on the other hand, is at subcritical conditions. The critical point of nitrogen is at $33.514 \mathrm{~atm}$ and $-146.958^{\circ} \mathrm{C}$.

Nitrogen experiments at a confining pressure of 850 psig were also conducted on the 2" diameter core. Experiment $\mathrm{H}$ was done prior to nitrogen experiments $\mathrm{K}$ and $\mathrm{L}$. The absolute permeability value obtained from Experiment $\mathrm{H}$ is $0.6 \mathrm{md}$. This is twice the absolute permeability of the $6.91 \mathrm{~cm}$ diameter core. This is due to the large fracture that cuts across the 2" diameter core at an angle of approximately 45 degrees relative to the core axis. Figure 4.5 shows the data for the three experiments.

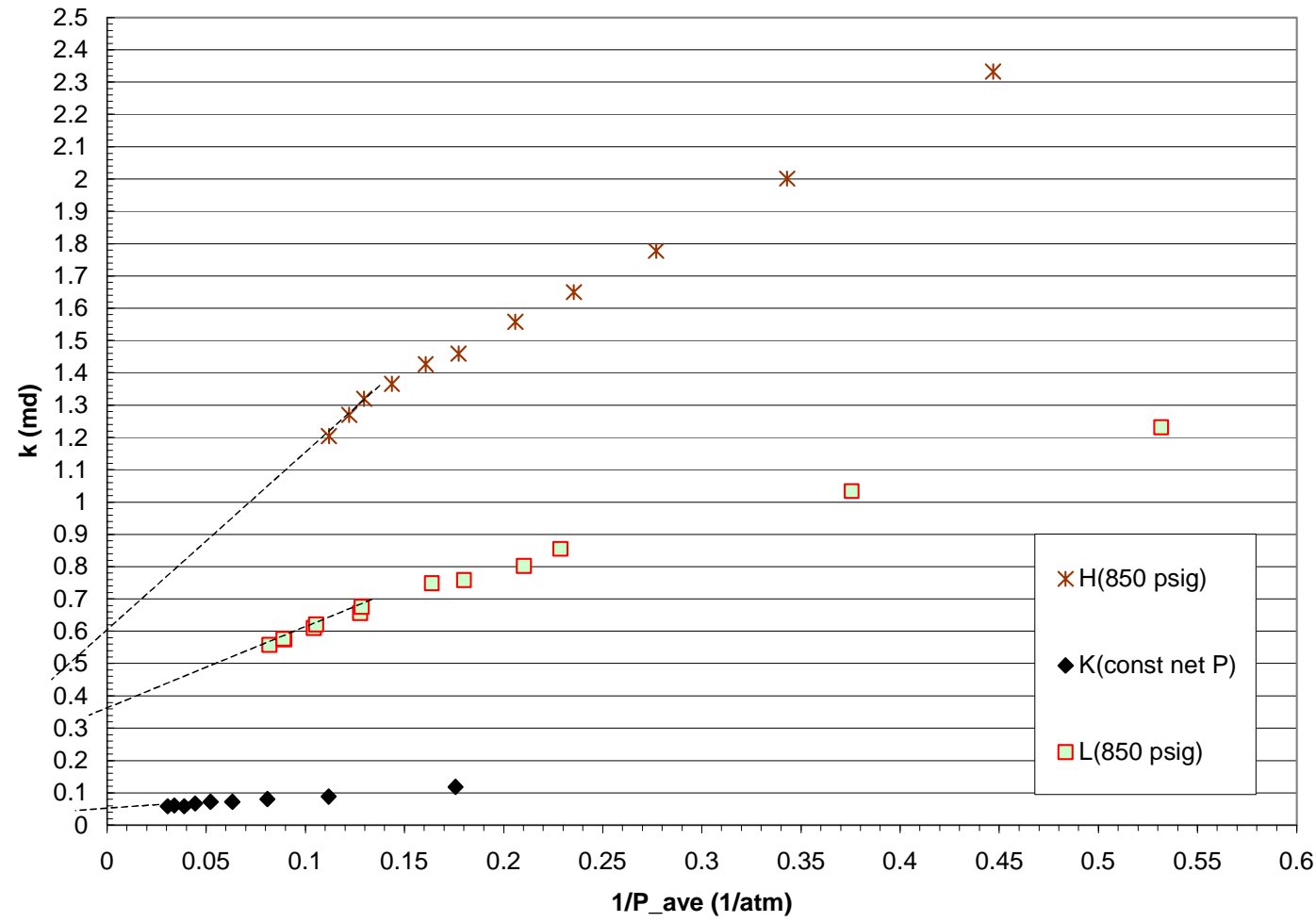

Figure 4.5: Nitrogen experiment results for the 2" diameter core.

Experiment $\mathrm{L}$ was done after several nitrogen-water relative permeability experiments. The results show a decrease in the absolute permeability from $0.6 \mathrm{md}$ to $0.35 \mathrm{md}$. Other researchers observed similar phenomena. Work by Bandis et al. (1981) showed that natural geological joints decrease in aperture as the number of loading cycles increase. Also, Myer (1991) measured flowrate change in metal casts of natural fractures and observed a decrease in flowrate due to an increase in number of loading cycles. This can be explained by the destruction and/or deformation of the fracture asperities causing the aperture to decrease. 
Normal

Stress

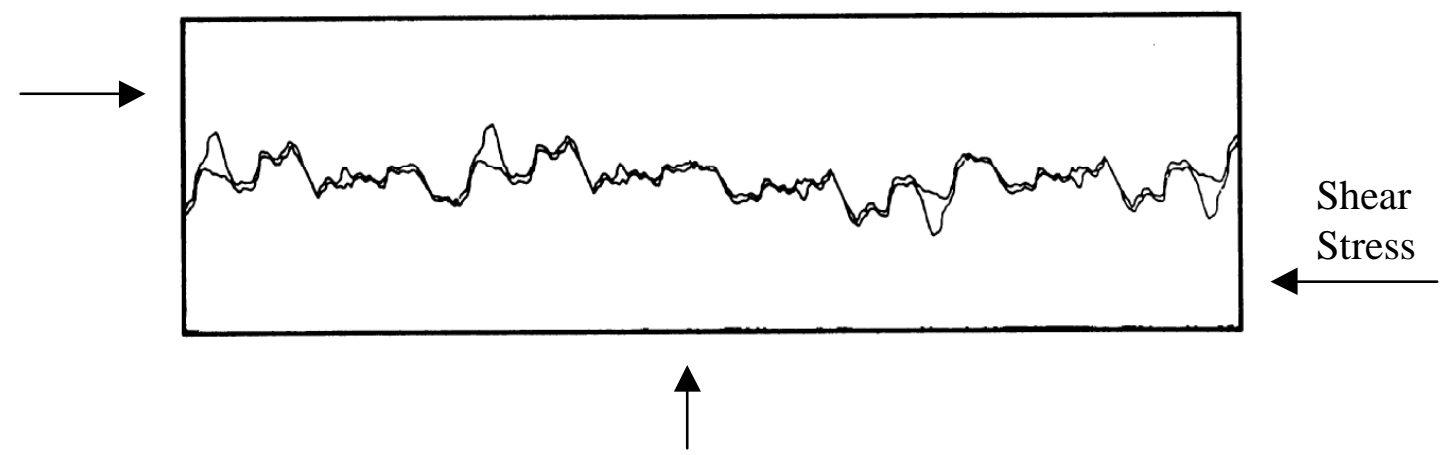

Figure 4.6: Schematic of a fracture surface. From Rock Fractures and Fluid Flow by the Committee on Fracture Characterization and Fluid Flow, National Research Council.

Considering the effect that the net effective stress has on the fluid flow an experiment, labeled L, was done at constant net normal stress. The result plots as a straight line on the $k$ vs $1 / p_{\text {ave }}$ axes and does not show the curvature at high confining pressures observed in the previous experiments. Experiment L gives an absolute permeability value of 0.048 md. This is very low and is unlikely to be correct because the experiment does not maintain the shear stresses on the core. As the confining pressure is changed the pressure on the core endplates also changes. Shear stress changes will cause asperities to position within voids causing a significant decrease in the flow path area. Figure 4.6 shows normal and shear stress orientations relative to a fracture surface.

Table 4.1: Absolute permeability and slip factor values from nitrogen experiments.

\begin{tabular}{|c|c|c|c|c|}
\hline Experiment & $\begin{array}{c}\text { Confining } \\
\text { Pressure } \\
(\mathrm{psig})\end{array}$ & $\begin{array}{c}\text { Absolute } \\
\text { Permeability } \\
(\mathrm{md})\end{array}$ & $\begin{array}{c}\text { Slip } \\
\text { Factor } \\
(\mathrm{atm})\end{array}$ & Remarks \\
\hline A & 500 & 0.38 & 9.091 & $6.91 \mathrm{~cm}$ dia. core \\
\hline B & 800 & 0.3 & 8.859 & $6.91 \mathrm{~cm}$ dia. core \\
\hline C & 850 & 0.29 & 7.356 & $6.91 \mathrm{~cm}$ dia. core \\
\hline D & 850 & 0.28 & 7.619 & $6.91 \mathrm{~cm}$ dia. core \\
\hline E & 1150 & 0.22 & 8.182 & $6.91 \mathrm{~cm}$ dia. core \\
\hline F & 850 & 0.22 & 8.182 & $6.91 \mathrm{~cm}$ dia. core \\
\hline H & 850 & 0.60 & 9.091 & $5.08 \mathrm{~cm}$ dia. core \\
\hline K & variable & 0.048 & 7.906 & $5.08 \mathrm{~cm}$ dia. core, constant normal net P \\
\hline L & 850 & 0.35 & 7.143 & $5.08 \mathrm{~cm}$ dia. core \\
\hline
\end{tabular}




\subsubsection{Water Injection Experiments}

Prior to the relative permeability experiments the absolute permeability was obtained by injecting water into the dried and vacuumed 2" diameter core. Flowrate was maintained constant at $10 \mathrm{ml} / \mathrm{min}$. Inlet pressure measurements are shown in Figure 4.7 .

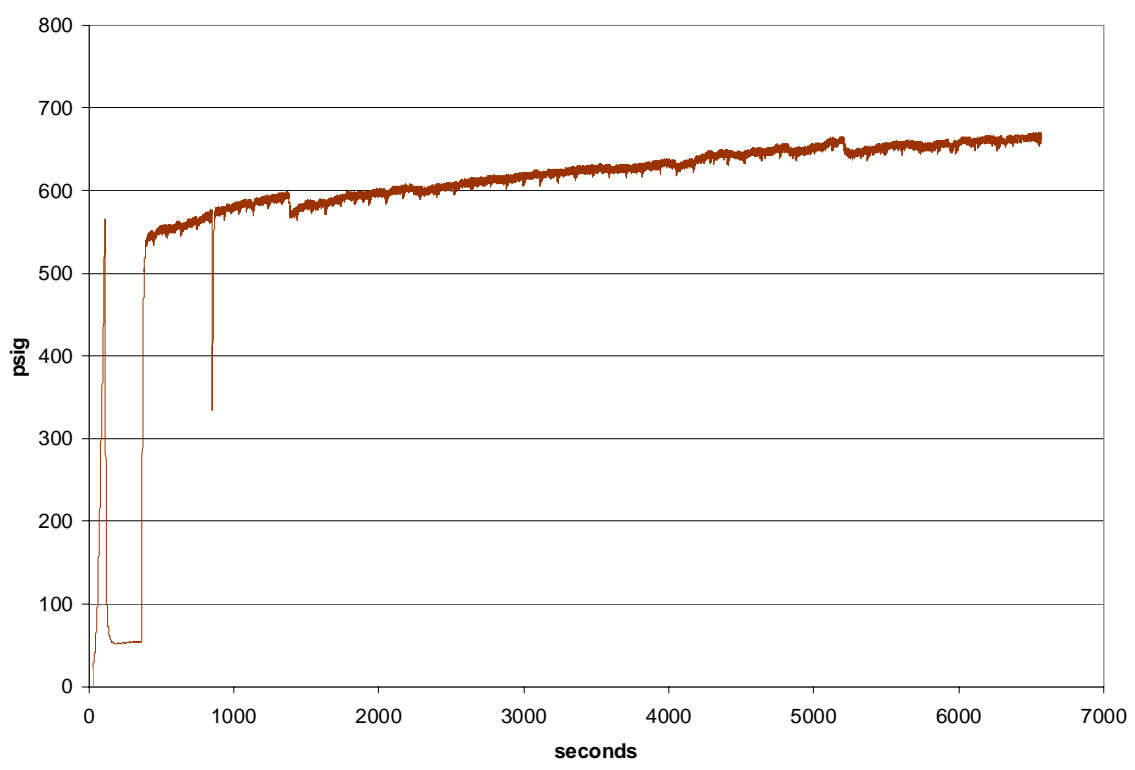

Figure 4.7: Pressure at inlet during water injection. Constant water flowrate at $10 \mathrm{ml} / \mathrm{min}$.

The calculated absolute permeability, using an inlet pressure of 669 psig and an outlet pressure of $11 \mathrm{psig}$, is $0.808 \mathrm{md}$.

The pore volume and porosity were obtained by weighing the core after this experiment. The pore volume is $3.87 \mathrm{~cm}^{3}$ and the porosity is $4.3 \%$.

Another absolute permeability experiment using water was done after several relative permeability experiment runs. Figure 4.8 shows the inlet pressure data for this experiment.

The inlet pressure demonstrates regularly occurring up and down cycles. The rise in each cycle is abrupt while the fall is relatively slow. The water pump does not cause the sudden rise because the recharge timing of the positive displacement pump is much shorter than the timing of the pressure spikes. 


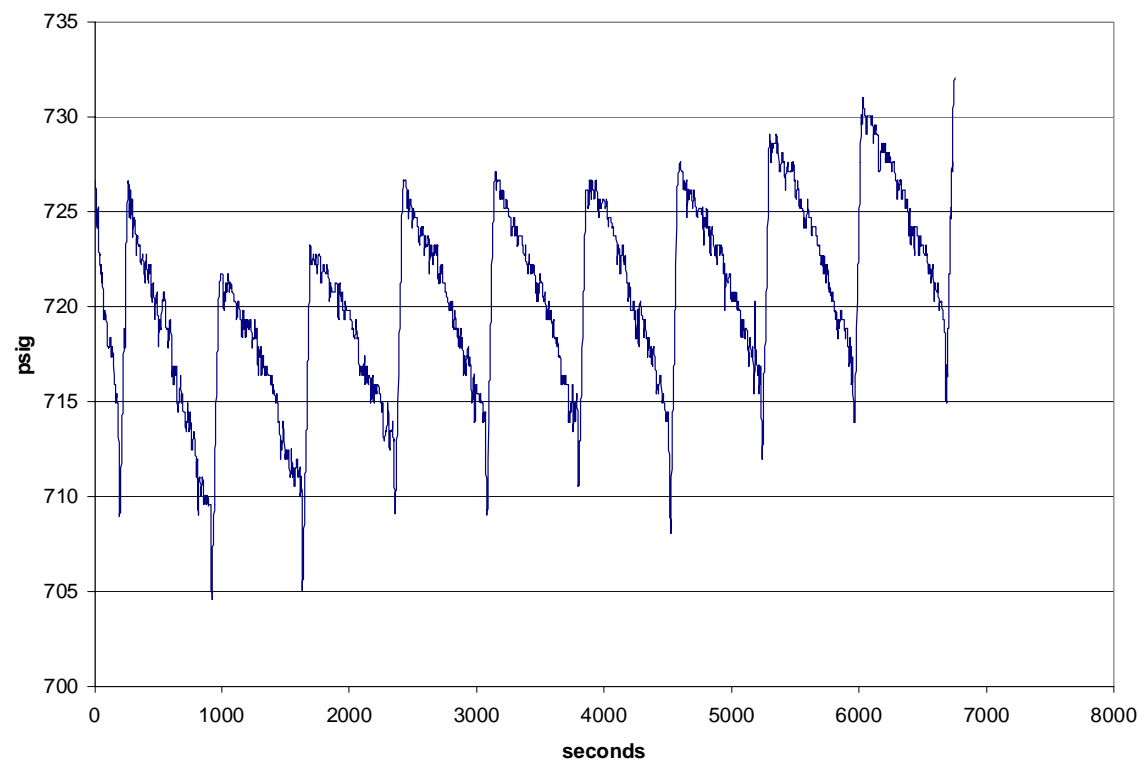

Figure 4.8: Pressure at inlet during water injection. Constant water flowrate at $14 \mathrm{ml} / \mathrm{min}$.

A conceptual model of fracture networks, assuming elastic rock fracture behavior, could provide an explanation. Water flows preferentially through the large fractures in the rock. In the case of the experiment, water was pumped at high pressure and high flowrate. This causes small fractures to stay open. However, pressure drops because the rock matrix and fracture network are capable of allowing more than $14 \mathrm{ml} / \mathrm{min}$ of fluid flow. When a certain low pressure is reached the small fractures close causing the sudden rise in pressure. The pump maintains a constant flowrate and will provide the required pressure that will reopen the small fractures. It is not necessary for many small fractures to close and open simultaneously. One small fracture may be the only link to a subset of fractures in the fracture network.

The drops in pressure are not likely due to fracture propagation/initiation because the absolute permeabilities obtained from the nitrogen experiments decreased as more experiments were conducted on the core. This suggests that fracture propagation has not occurred and if it has only to a degree much less significant than fracture aperture changes due to destruction of asperities.

The core is known to be heterogeneous (i.e. contains veins) and this causes discontinuous fracture propagation at the interface of different rock materials, Figure 4.9. Discontinuous fracture propagation is known to be the preferential mechanism of fracture initiation induced by another fracture in the adjacent material. This hinders the creation of connected fracture networks even if the rock is subjected to high stresses. Continued application of load cycles will later cause these fractures to connect. This connection of fractures may have occurred in Experiment 2 of the nitrogen-water relative permeability experiment. 


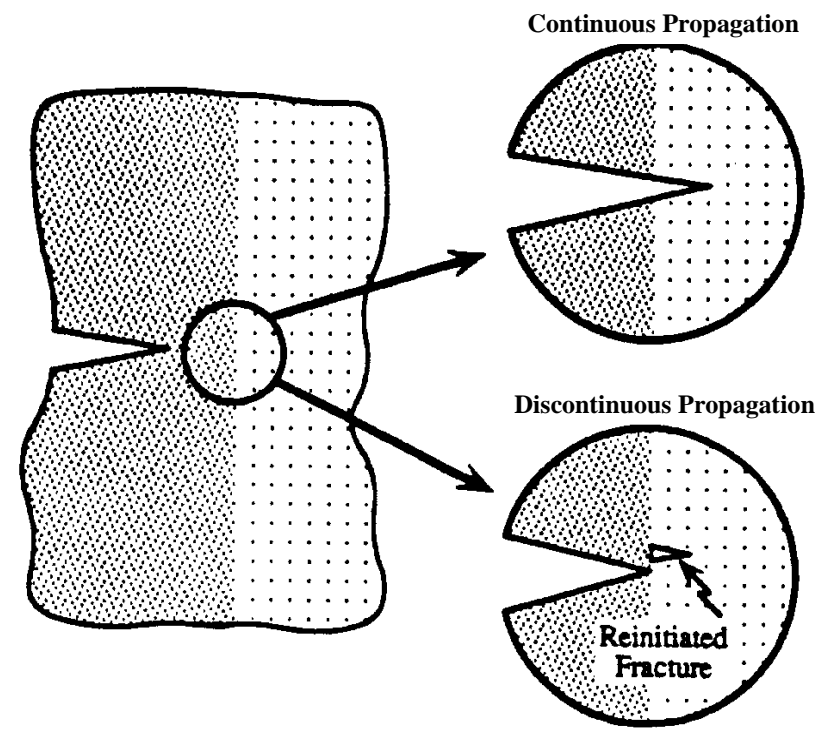

Figure 4.9: Continuous vs discontinuous propagation across interface of two rock materials.

From Renshaw and Pollard (1995).

The general pressure trend in Figure 4.8 is increasing. There are several possible reasons for this. The effect may be due to swelling clays and/or strain hardening of the fractures. Fines may also be accumulating.

Since steady pressures were not achieved at $14 \mathrm{ml} / \mathrm{min}$ the flowrate was reduced to 2 $\mathrm{ml} / \mathrm{min}$. The inlet pressure measurements are shown in Figure 4.10.

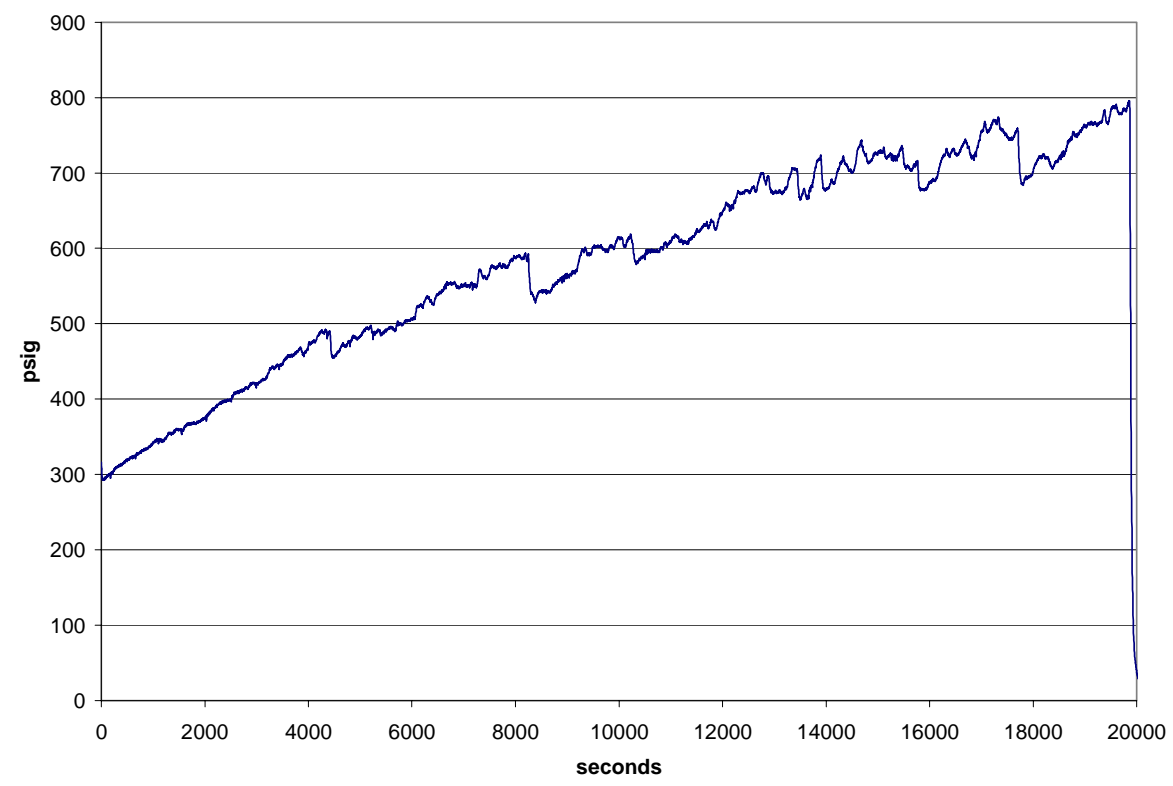

Figure 4.10: Pressure at inlet during water injection. Constant water flowrate at $2 \mathrm{ml} / \mathrm{min}$.

The fracture network model discussed previously can be used to explain the inlet pressure behavior for the $2 \mathrm{ml} / \mathrm{min}$ experiment. The low flowrate causes the pressure rise to be 
slower than the fall in pressure. At high inlet pressures, the fractures are not very stable because the low net stress and low flowrate is not enough to maintain the fracture openings. Thus, pressure fluctuations at 700 psig and above are observed. Again, fines may also be the culprits causing the fluctuations.

Water at the outlet was filtered to determine if fines were being produced. No fines were found. This does not eliminate the possibility that some fines were trapped within the core.

Steady state was not achieved because the pressure reached the maximum pump pressure limit. Due to this the flowrate was reduced further to $0.1 \mathrm{ml} / \mathrm{min}$.

The inlet pressure data of the water injection experiment at $0.1 \mathrm{ml} / \mathrm{min}$ is shown in Figure 4.11. After three days, the pressure still had not reached steady state. Cycles of slow pressure rise and sudden drops similar to the $2 \mathrm{ml} / \mathrm{min}$ experiment were observed.

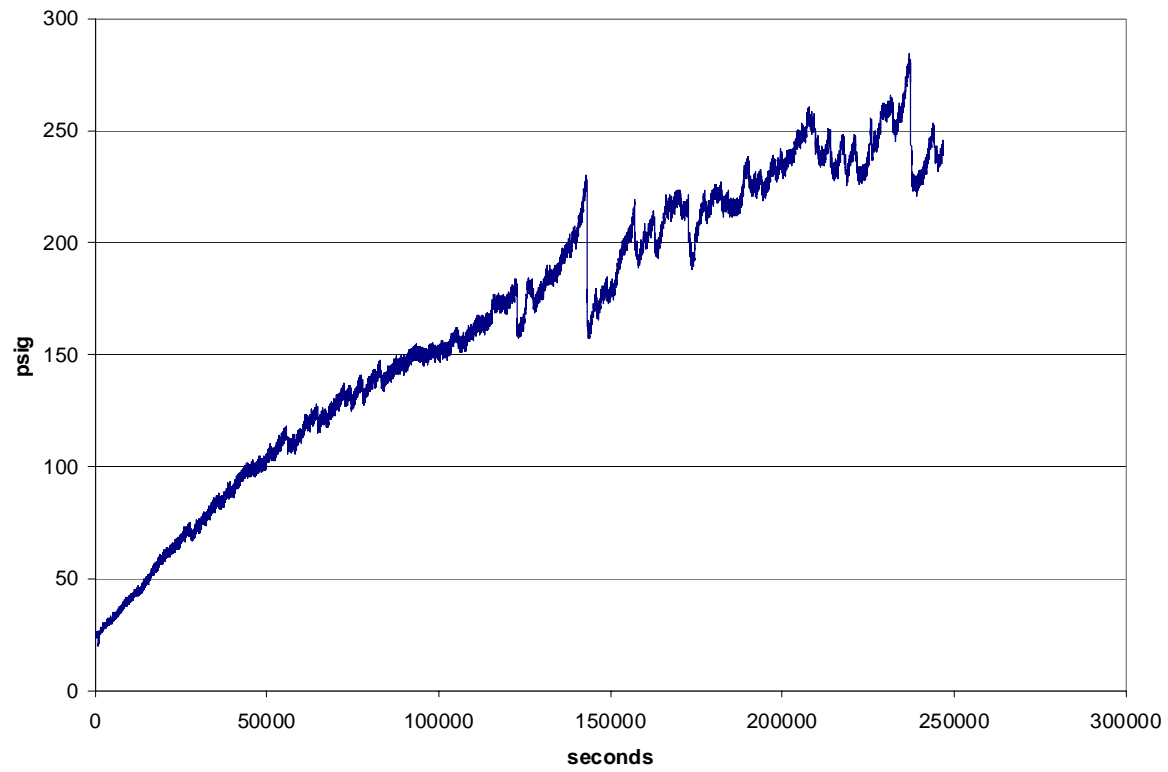

Figure 4.11: Pressure at inlet during water injection at constant water flowrate of $0.1 \mathrm{ml} / \mathrm{min}$.

To get a sense of what is happening with the rock, calculations of absolute permeability were made at pressures that are judged to be relatively stable.

Table 4.2: Absolute permeability values from water injection experiments.

\begin{tabular}{|c|c|c|c|}
\hline Experiment & $\begin{array}{c}\text { Flowrate } \\
(\mathrm{ml} / \mathrm{min})\end{array}$ & $\begin{array}{c}\text { Stable Pressure } \\
(\mathrm{psig})\end{array}$ & $\begin{array}{c}\text { Absolute } \\
\text { Permeability (md) }\end{array}$ \\
\hline 1 & 10 & 668 & 0.8082 \\
\hline 2 & 14 & 730 & 1.0445 \\
\hline 3 & 2 & 730 & 0.1492 \\
\hline 4 & 0.1 & 230 & 0.0244 \\
\hline
\end{tabular}




\subsection{Resistivity Experiments}

Resistivity measurements were used to determine the average water saturation in the core. Experiments were conducted on two disc-shaped rocks before establishing the resistivitysaturation relationship for the 2" diameter core.

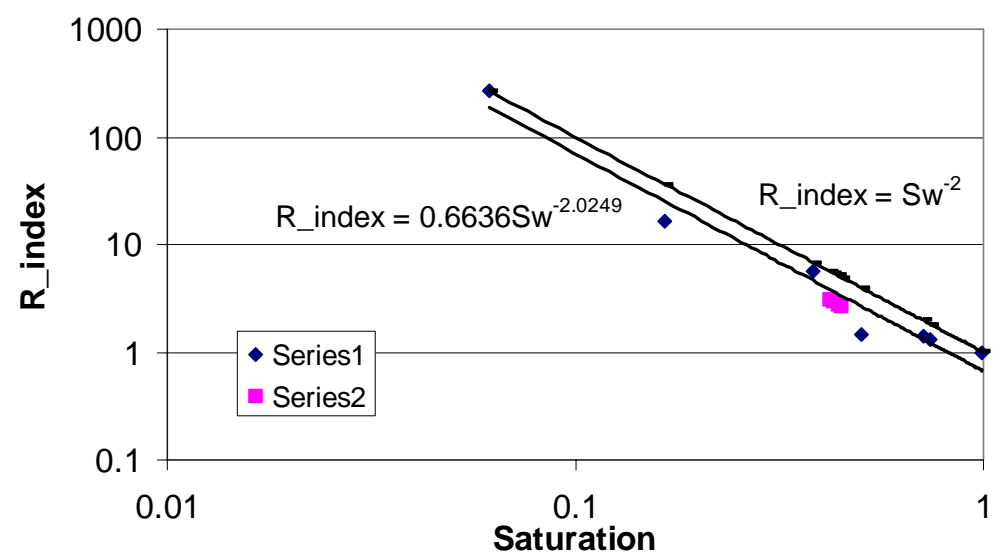

Figure 4.12: $R_{\text {index }}$ versus water saturation for homogeneous rock.

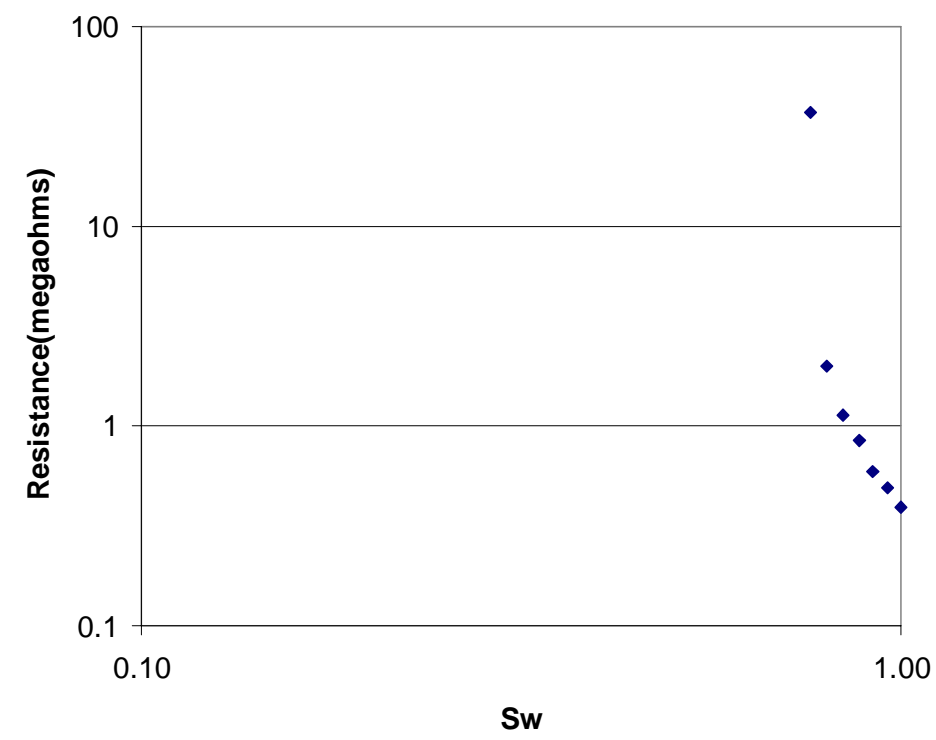

Figure 4.13: Resistance versus water saturation for heterogeneous rock.

Resistivity experiment on the disc-shaped homogeneous rock showed a linear relationship between $R_{\text {index }}$ and saturation in a log-log plot, Figure 4.12. Series 1 and Series 2 are different experiments on the same rock sample. This is very similar to the result obtained by Archie (1950). For the heterogeneous rock, resistance readings were only obtained for a saturation range of 1 to 0.76 , Figure 4.13 . This is due to water drying out at the point of contact of the electrodes while most of the water is concentrated in the visible fractures of 
the core. This is a challenge in the application of the resistivity technique to saturation measurements in heterogeneous rocks.

To overcome the difficulty in measuring resistance at low water saturations several resistors and rheostats were connected in parallel with the core, thereby reducing overall resistance below the resistance meter limit of $40 \mathrm{M} \Omega$. The result of the resistivity experiment on the 2" diameter core is shown in Figure 4.14.

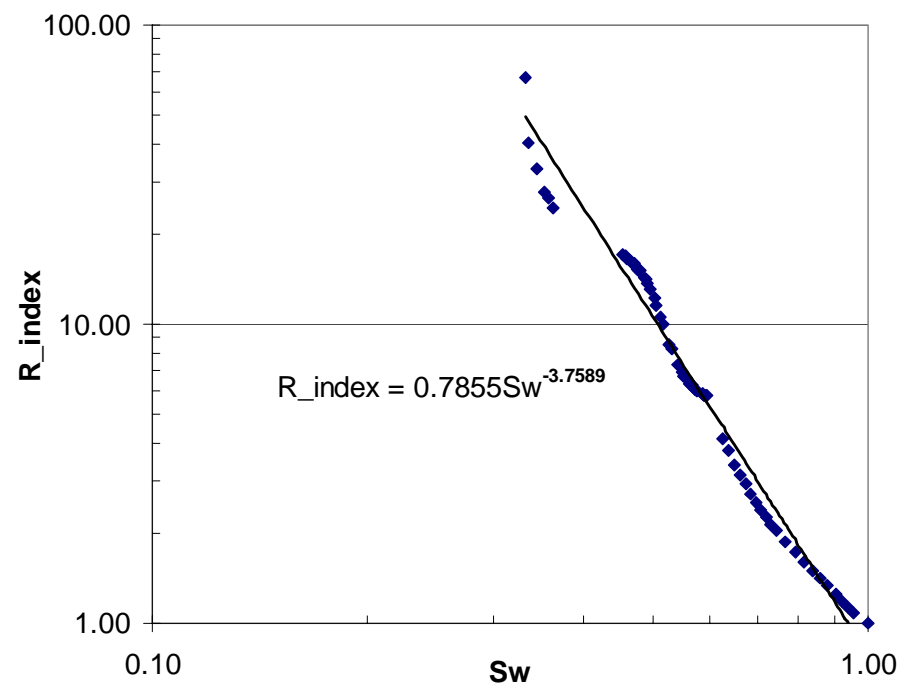

Figure 4.14: Resistance versus water saturation for 2" diameter core from The Geysers.

The water saturation of the core was then determined by the equation,

$$
S_{w}=\left(\frac{0.7855}{R_{-} \text {index }}\right)^{\frac{1}{3.7589}}
$$

The irreducible water saturations were obtained after nitrogen experiments $\mathrm{H}$ and $\mathrm{L}$. The irreducible nitrogen saturations were determined upon completion of water injection experiments conducted after nitrogen experiments $\mathrm{H}$ and $\mathrm{L}$.

Table 4.3: Irreducible water saturation.

\begin{tabular}{|c|c|c|}
\hline Nitrogen Experiment & Weighing Method & Resistivity Method \\
\hline Experiment H & $12.9 \%$ & $15.43 \%$ \\
\hline Experiment L & $17.57 \%$ & $14.3 \%$ \\
\hline
\end{tabular}


Table 4.4: Water saturation at irreducible nitrogen gas saturation.

\begin{tabular}{|c|c|c|}
\hline $\begin{array}{c}\text { Water Injection } \\
\text { Experiment }\end{array}$ & Weighing Method & Resistivity Method \\
\hline Experiment 1 & $79.1 \%$ & $78.76 \%$ \\
\hline Experiment 2 & $78.55 \%$ & $80.89 \%$ \\
\hline
\end{tabular}

The irreducible water saturation is approximately $15 \%$ and the irreducible gas saturation is about $20 \%$. Evaporation has a bigger effect on the measurements done at irreducible gas saturation than at irreducible water saturation because more water is exposed to the atmosphere. This may cause lower mass readings for the core at irreducible nitrogen saturation. Therefore, the water saturation at irreducible nitrogen gas saturation may be higher than the values in Table 4.4.

The resistivity readings provide acceptable values and can be used to give saturation estimates for similar experiments.

\subsection{Nitrogen-Water Relative Permeability}

\subsubsection{Eclipse Simulation}

Flow simulations were done using Eclipse to determine the saturation distribution behavior in the core when nitrogen and water are injected simultaneously. Also, the simulation provides estimates of the time required to achieve steady state. Injection flowrates were controlled in the different simulations. Nitrogen and water were injected at the middle block of the left face of the core model and produced at the middle block of the right face.

Matrix porosity of $4.3 \%$ and permeability of $0.5 \mathrm{md}$ were used. The fracture was simulated by a double porosity model where the fracture was given a porosity of $100 \%$. 

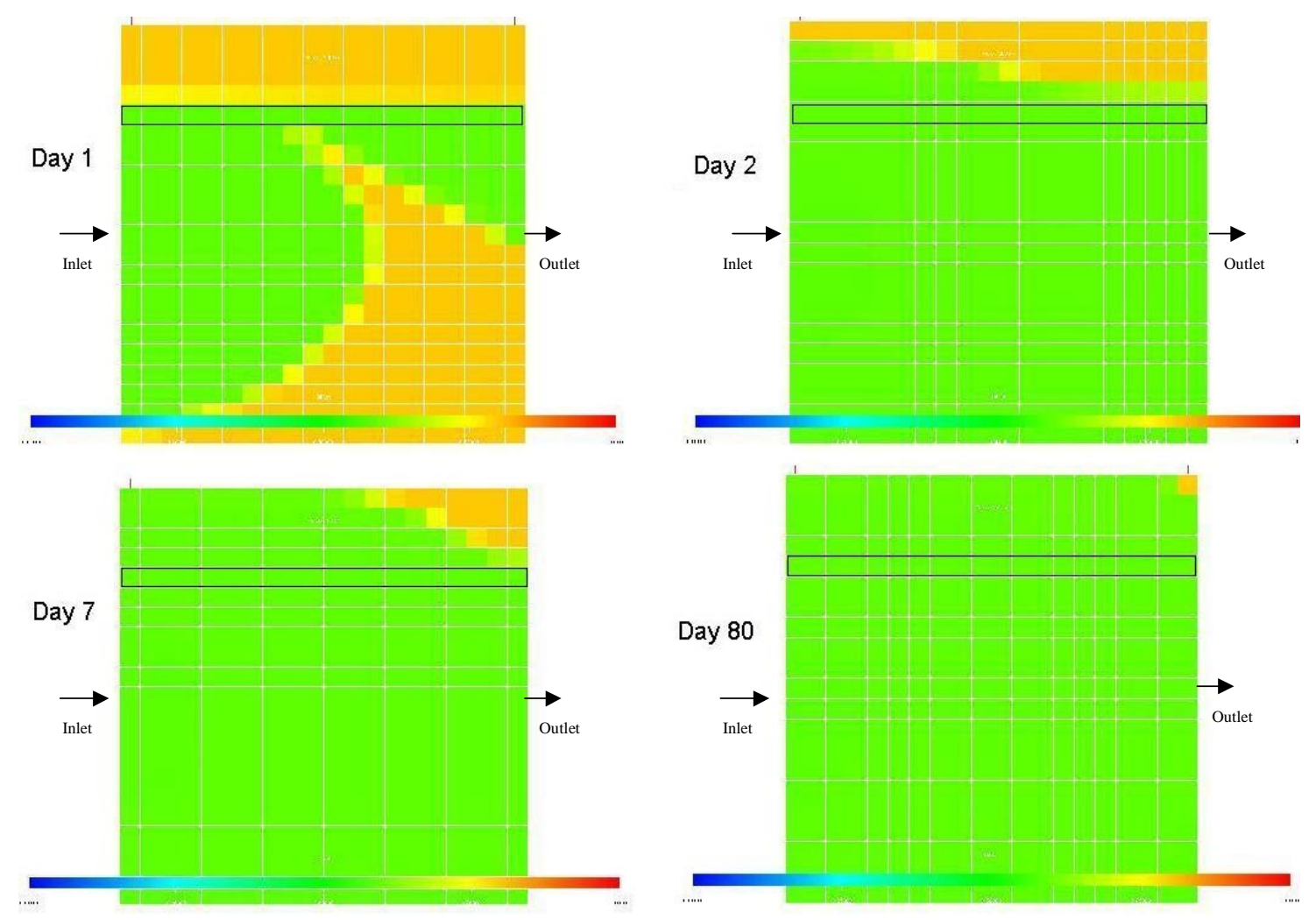

Figure 4.15: Saturation map for imbibition with horizontal fracture connecting left and right faces of the core model. Fracture is indicated by the black rectangle.

Steady-state uniform saturation was attained in approximately 80 days as shown in Figure 4.15. Red in the graduated color scale indicates $100 \%$ nitrogen gas saturation and blue indicates $100 \%$ water saturation.

A single fracture or a fracture network that horizontally connects the left and right faces of the core may not be the case for the 2" diameter core used in this study. Thus, further simulations were done for an inclined fracture and for a horizontal fracture that does not extend completely from the left to the right faces of the core model. 

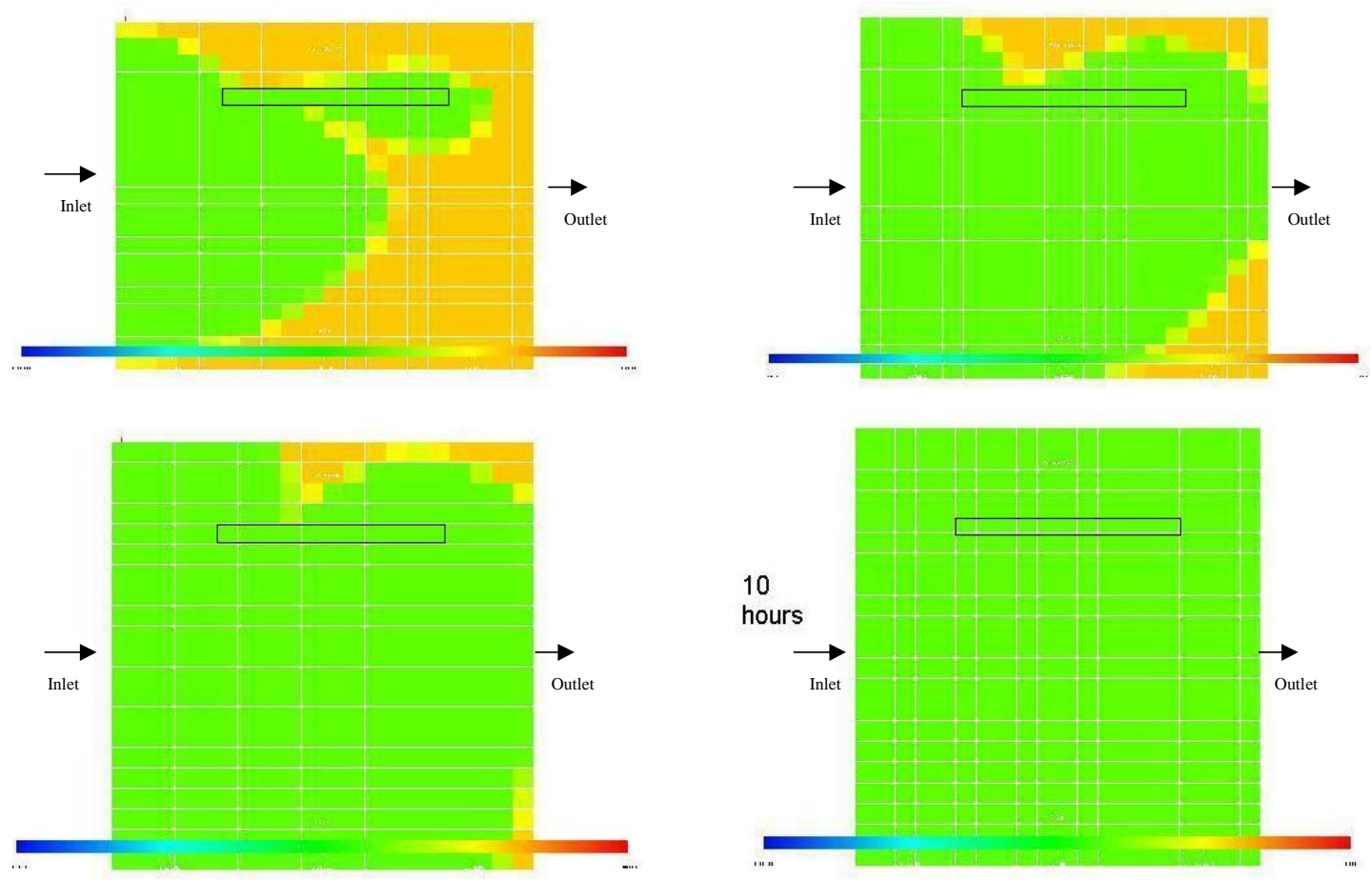

Figure 4.16: Saturation map for imbibition with short horizontal fracture. Fracture is indicated by black rectangle.
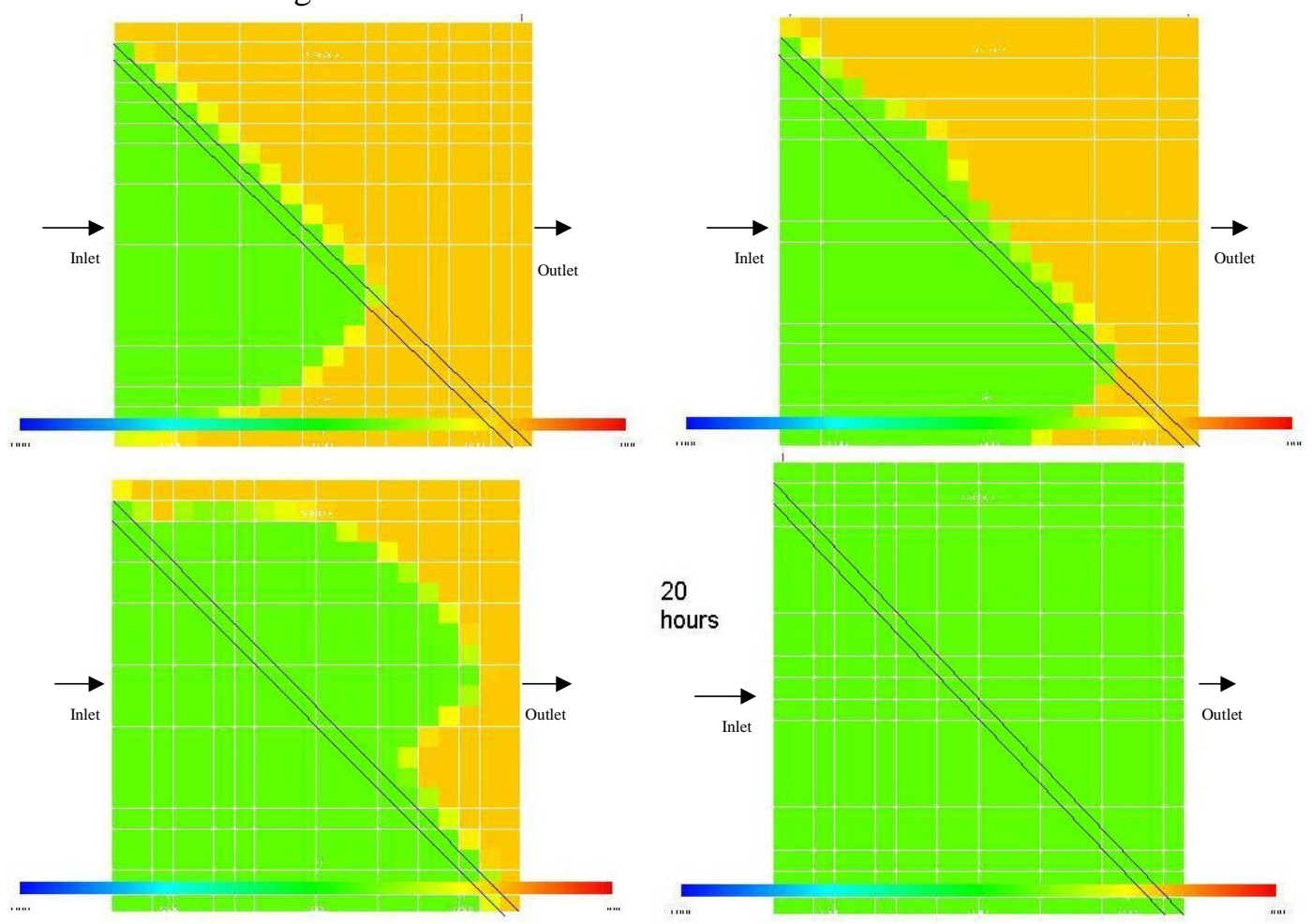

Figure 4.17: Saturation map for imbibition with inclined fracture connecting left and right faces of the core model. Fracture is located between the black lines. 
For simulations with a short horizontal fracture, located in the upper middle of the core, steady-state uniform saturation was reached in less than 10 hours. This is shown in Figure 4.16.

Simulations with an inclined fracture extending from the left to the right of the core achieved steady state in 20 hours, Figure 4.17.

Other drainage and imbibition simulations at different gas and water injection flowrates that were done all reached steady state in less than 24 hours.

Therefore, for an ideal fractured core, steady-state uniform saturation can be realized in 24 hours or less. An ideal fractured core will have no clay swelling, fines, and fracture networks that connect the left and right faces of the core horizontally.

\subsubsection{Relative Permeability at Endpoint Saturations}

The first set of endpoint saturation relative permeability experiments is labeled Experiment 1 and the next set Experiment 2.

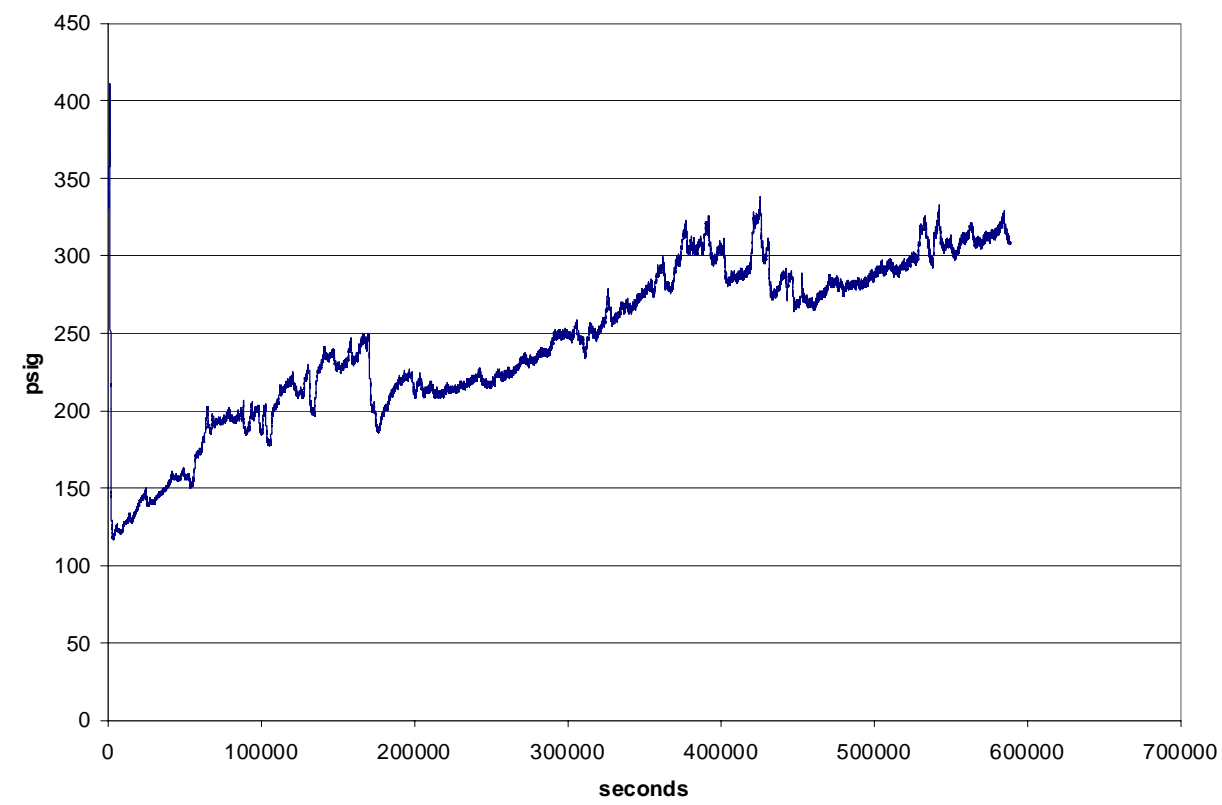

Figure 4.18: Pressure at inlet during water injection at constant water flowrate of $0.05 \mathrm{ml} / \mathrm{min}$. From Experiment 1.

The approximate steady state was taken to be at an inlet pressure of $300 \mathrm{psig}$. The pressure fluctuations are erratic and difficult to explain. The conceptual model developed and applied to the water absolute permeability experiment results is inadequate. The pressure spikes in Figure 4.18 can be attributed to interference between nitrogen and water flows in addition to the fracture behavior described in the conceptual model. 
Steady-state for the gas injection of Experiment 1 was reached at a pressure of 78 psig and a flowrate of $0.16 \mathrm{~L} / \mathrm{min}$. The inlet pressure and flowrate data are shown in Figure 4.19.

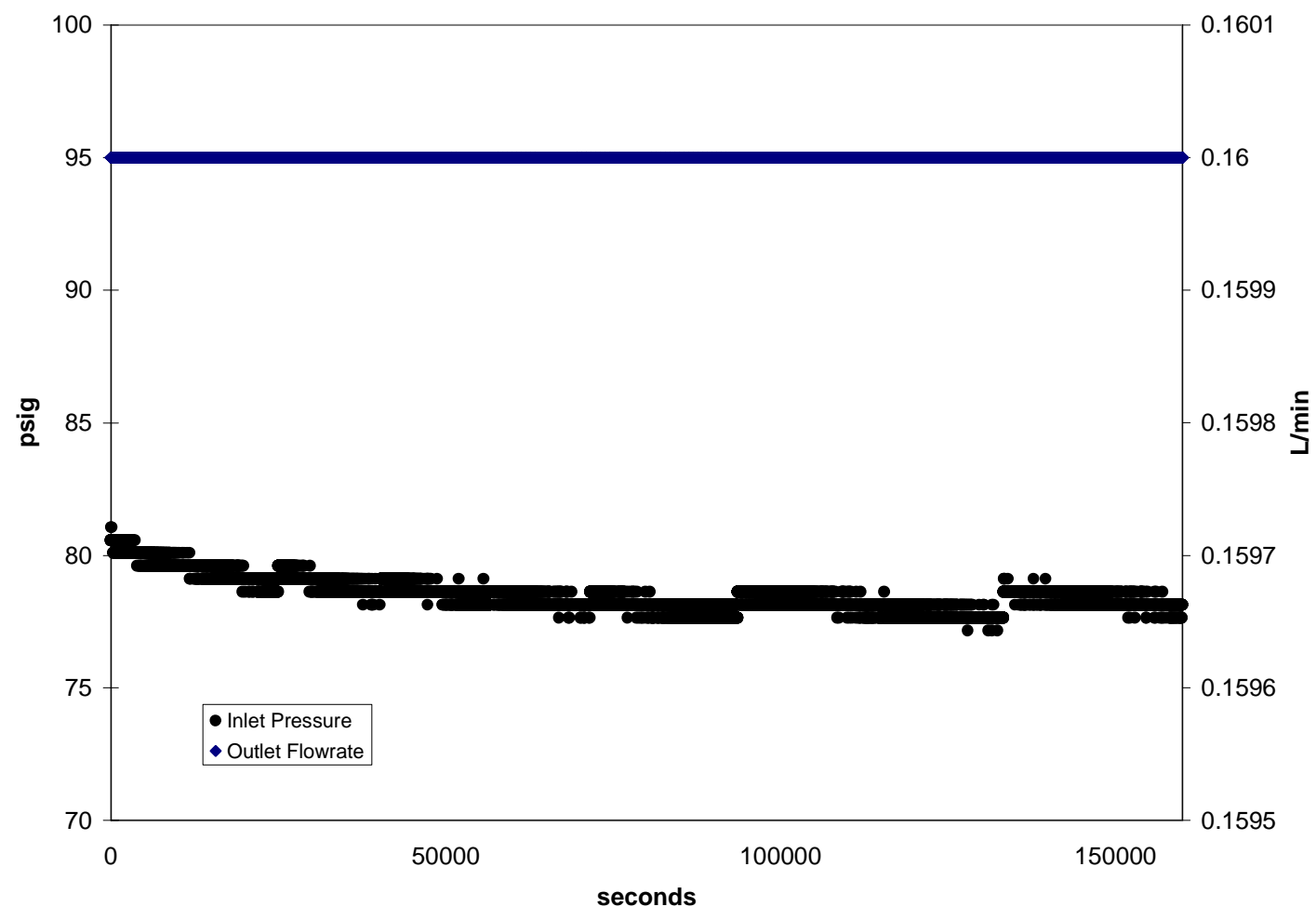

Figure 4.19: Pressure and flowrate at inlet during gas injection. From Experiment 1.

Experiment 2 results at irreducible gas saturation are presented in Figure 4.20. Steady state was at an inlet pressure of $580 \mathrm{psig}$. The sudden pressure drop of $350 \mathrm{psi}$ at around 48000 seconds did not affect the cumulative water readings at the outlet and no changes were observed with the water pump. There was no gas seen with the deaerated water being fed to the pump. Such a huge pressure change can be caused by the formation of new flow pathways. This hypothesis is supported by the fact that steady state was realized at a pressure lower than $650 \mathrm{psig}$, where the pressure started to decline. The pathways may not have been accessible initially because of trapped nitrogen or closed fractures. However, in Experiment 1 where it is logical to assume similar events to occur the pressure drops observed were around $50 \mathrm{psi}$ and did not occur as rapidly as the 350 psi drop in Experiment 2. It is therefore likely that the pressure drop in Experiment 2 was caused by fracture propagation. For materials with flaws, stress concentration will be high and fracture propagation/initiation occur well below the material's tensile strength. 


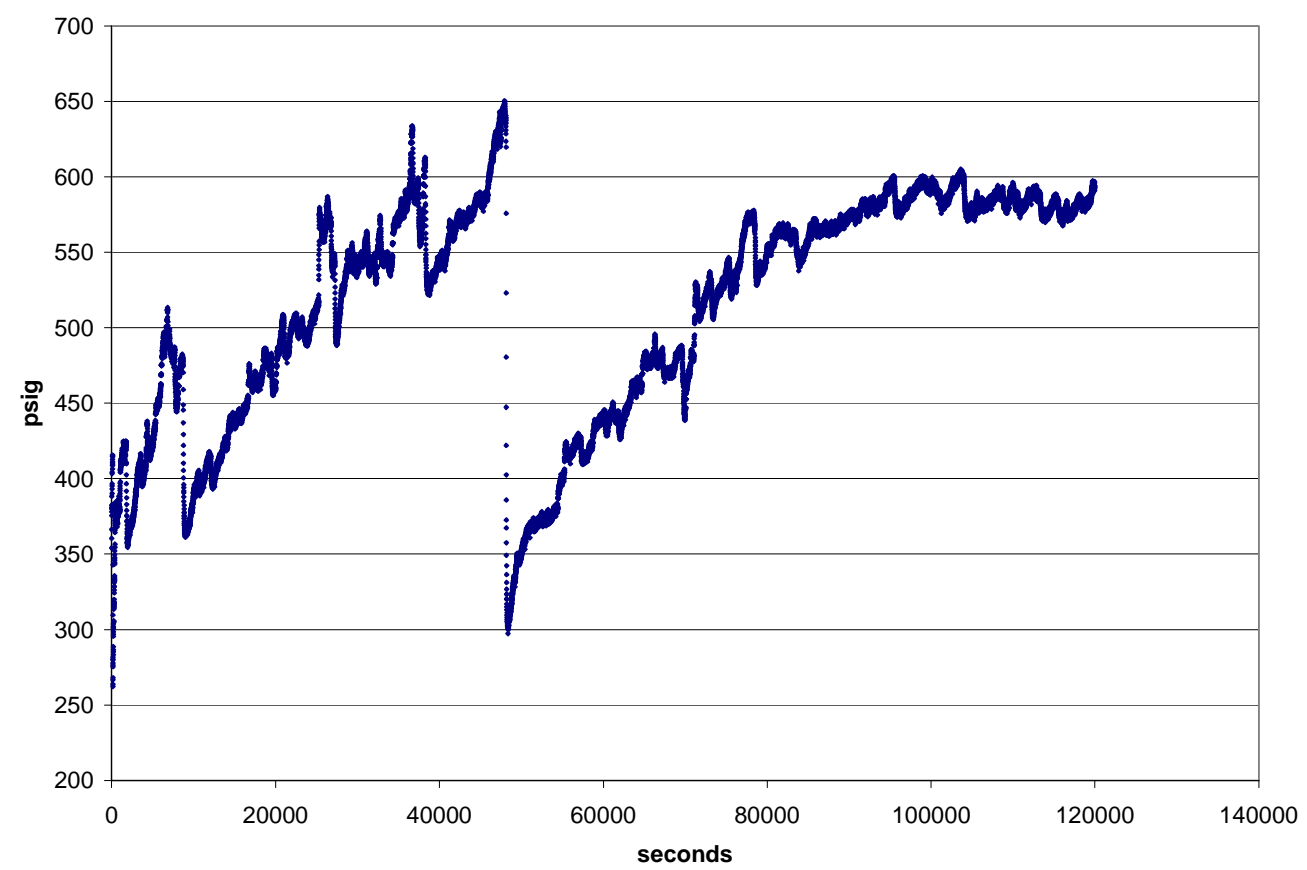

Figure 4.20: Pressure at inlet during water injection at constant water flowrate of $0.5 \mathrm{ml} / \mathrm{min}$. From Experiment 2.

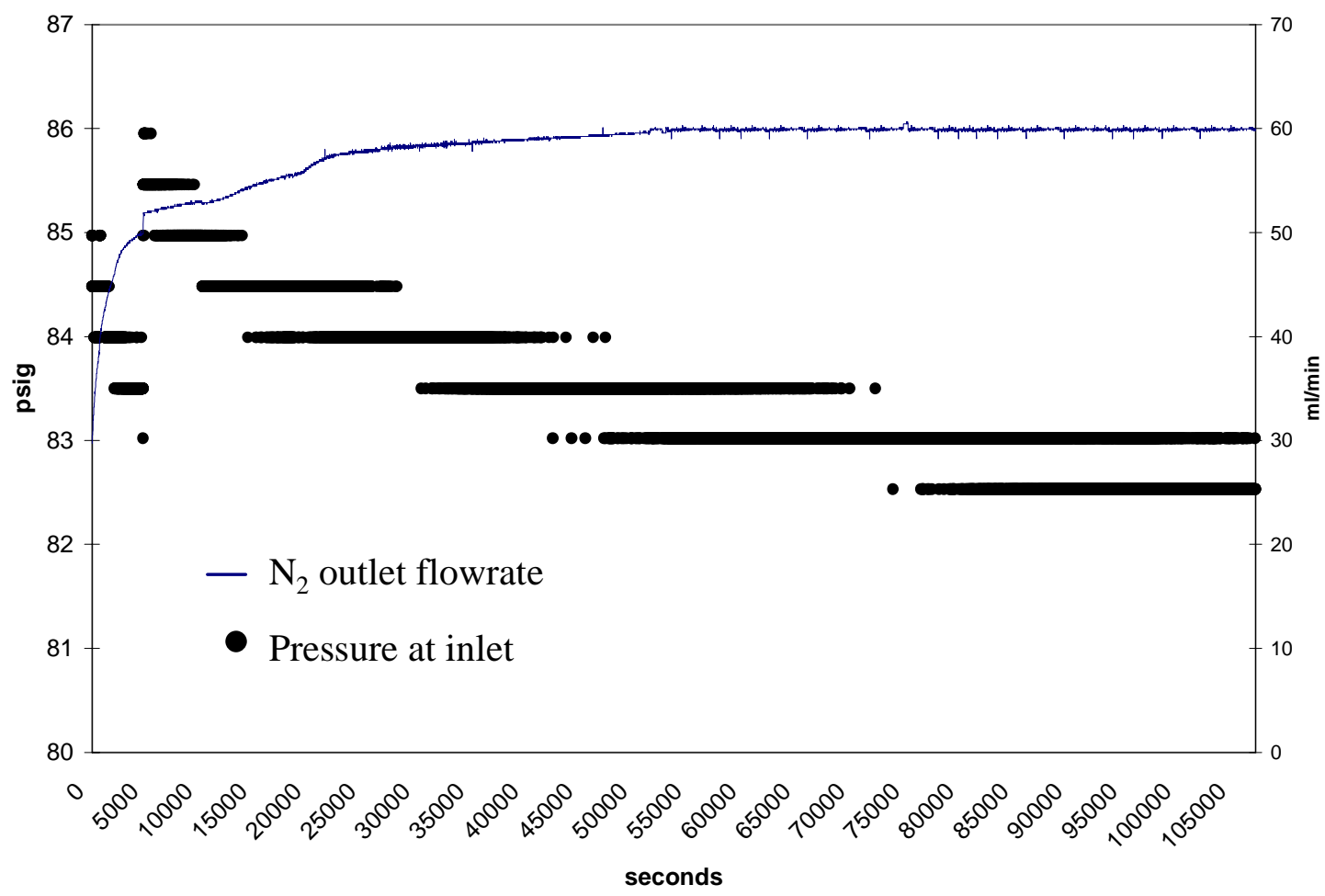

Figure 4.21: Pressure and flowrate at inlet during gas injection. From Experiment 2. 
Experiment 2 results at irreducible water saturation are shown in Figure 4.21. Steady state was at $83 \mathrm{psig}$ and $60 \mathrm{ml} / \mathrm{min}$.

The relative permeabilities using the different calculated absolute permeabilities and slip factors are listed in Tables 4.5 through 4.8.

Table 4.5: Nitrogen gas relative permeability from Experiment 1.

\begin{tabular}{|c|c|c|l|}
\hline$k_{r g}$ & $k_{a b s}$ & $b$ & \multicolumn{1}{c|}{ Remarks } \\
\hline 0.957 & 0.6 & 9.091 & $k_{a b s}$ and $b$ from $\mathrm{N}_{2}$ gas experiment $\mathrm{H}$ \\
\hline 0.711 & 0.808 & 9.091 & $\begin{array}{l}k_{a b s} \text { from water injection experiment @ } 10 \mathrm{ml} / \mathrm{min} \\
b \text { from } \mathrm{N}_{2} \text { gas experiment } \mathrm{H}\end{array}$ \\
\hline
\end{tabular}

Table 4.6: Nitrogen gas relative permeability from Experiment 2.

\begin{tabular}{|c|c|c|c|}
\hline$k_{r g}$ & $k_{a b s}$ & $b$ & \multicolumn{1}{c|}{ Remarks } \\
\hline 0.709 & 0.35 & 7.143 & $k_{a b s}$ and $b$ from $\mathrm{N}_{2}$ gas experiment L \\
\hline 0.238 & 1.0445 & 7.143 & $\begin{array}{l}k_{a b s} \text { from water injection experiment @ } 14 \mathrm{ml} / \mathrm{min} \\
b \text { from } \mathrm{N}_{2} \text { gas experiment L }\end{array}$ \\
\hline
\end{tabular}

Table 4.7: Water relative permeability from Experiment 1.

\begin{tabular}{|c|c|l|}
\hline$k_{r w}$ & $k_{a b s}(\mathrm{md})$ & $k_{a b s}$ obtained from \\
\hline 0.0134 & 0.6 & $\mathrm{~N}_{2}$ gas experiment $\mathrm{H}$ \\
\hline 0.0099 & 0.808 & Water injection experiment @ $10 \mathrm{ml} / \mathrm{min}$ \\
\hline
\end{tabular}

Table 4.8: Water relative permeability from Experiment 2.

\begin{tabular}{|c|c|l|}
\hline$k_{r w}$ & $k_{a b s}(\mathrm{md})$ & $k_{a b s}$ obtained from \\
\hline 0.1348 & 0.35 & $\mathrm{~N}_{2}$ gas experiment L \\
\hline 0.0452 & 1.0445 & Water injection experiment @ $14 \mathrm{ml} / \mathrm{min}$ \\
\hline
\end{tabular}

The absolute permeabilities from the water injection experiments at $0.1 \mathrm{ml} / \mathrm{min}$ and 2 $\mathrm{ml} / \mathrm{min}$ are highly suspect because the water pump shut down during the $2 \mathrm{ml} / \mathrm{min}$ water injection experiment upon reaching the maximum pressure limit. The $0.1 \mathrm{ml} / \mathrm{min}$ water injection experiment followed the experiment at $2 \mathrm{ml} / \mathrm{min}$. Air may have entered the core when the pump stopped. Thus, the relative permeability values obtained from the 0.1 $\mathrm{ml} / \mathrm{min}$ and $2 \mathrm{ml} / \mathrm{min}$ experiments are erroneous.

Prior to the nitrogen experiment, L, the slip factor used was obtained from experiment $\mathrm{H}$. 
Numerical simulations by Pruess and Tsang (1990) and Pyrak-Nolte et al. (1990) indicate significant phase interference resulting in the sum of relative permeabilities being less than 1. The sum of the relative permeabilities for Experiment 1 and Experiment 2 are all less than 1 .

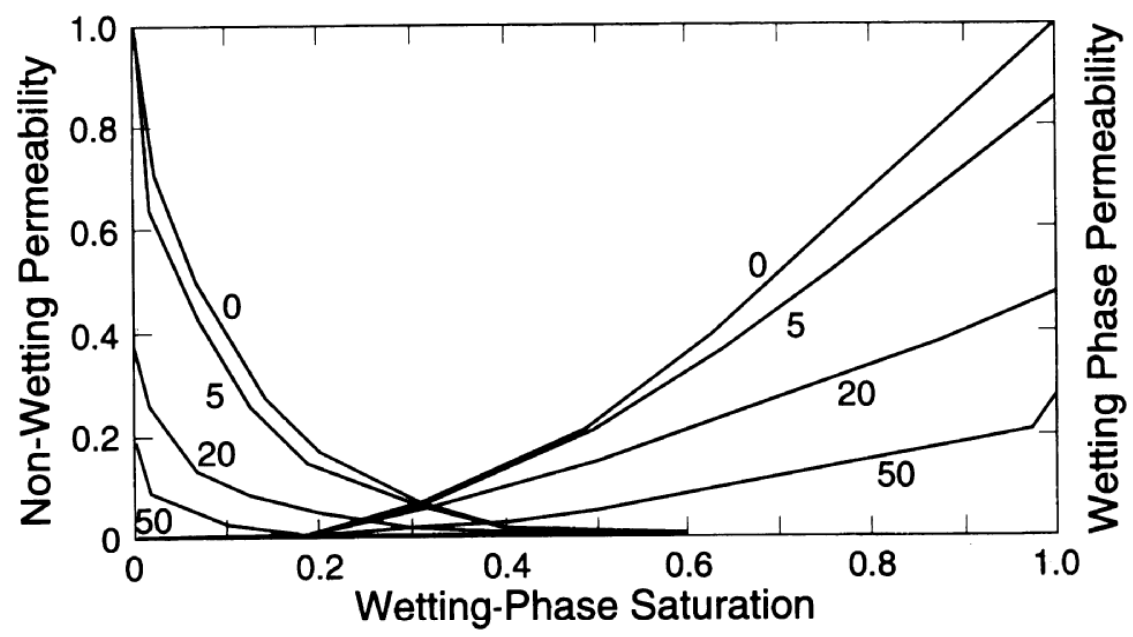

Figure 4.22: Simulation of effect of stress on relative permeabilities for a reduction in aperture of 5, 20, and 50 units of aperture. From Pyrak-Nolte et al. (1990).

The value of $k_{r g}$ is much higher than $k_{r w}$ at the endpoint saturations. The simulations by Pyrak-Nolte et al. (1990) show that this can occur at large apertures, as in Figure 4.22.

More insight may be gained by using the modified cubic flow equations for rough fractures by Cook et al. (1990). This equation is for single-phase flow only. Since the experiments were done at irreducible saturations then the equation may be applied for purposes of determining parameter effects and not for obtaining definite numerical answers.

$$
q=\left(\frac{b^{3}}{12 \mu}\right)\left(\frac{1-d}{1+d}\right) \frac{1}{f} \nabla p+q_{\infty}
$$

where $b$ is a representative aperture

$\mu$ is the dynamic viscosity

$d$ is the ratio of the contact area of asperities to the total fracture area

$f$ is the friction factor

$\nabla p$ is the pressure gradient

$q_{\infty}$ is the irreducible flow, or the flow if there were no fractures

$q$ is the actual flowrate 
Equating this to $q=\left(k k_{r} A / \mu\right) \nabla p$ and solving for $k_{r}$,

$$
k_{r}=\left(\frac{b^{3}}{12}\right)\left(\frac{1-d}{1+d}\right) \frac{1}{f} \frac{1}{k A}+\frac{q_{\infty}}{q}
$$

The ratio $q d q$ will be less than 1 . Intuitively, this ratio will be lower for water than for nitrogen gas.

Also, assuming that $b$ and $d$ are the same for Experiment 1 and Experiment 2, then changes in the friction factor will determine the differences in relative permeability. The water flow will have lower Reynolds number and, consequently, higher friction factor than the gas flow. Thus, $k_{r w}$ will be less than $k_{r g}$ at irreducible saturations.

The wetting property of water may also have a decreasing effect on the friction factor of the gas flow. At irreducible water saturation, water will occupy the small spaces in the fracture surfaces and will reduce the surface roughness. A smoother surface will have a lower friction factor. The effect of the decrease in void volume, due to the presence of water within the fractures, may not be as significant as the reduction in surface roughness.

\subsubsection{Nitrogen and Water Injection}

Several nitrogen-water relative permeability experiments were conducted by injecting nitrogen and water into the core simultaneously. None of these experiments realized steady state.

The first few experiments were conducted at constant inlet flowrates for both water and nitrogen. Figure 4.23 shows the inlet pressure behavior of one of these experiments. The general pressure trend tends to stabilize at 60 psi. However, 100 psi pressure spikes are evident. This strange phenomenon may be explained by the fracture network conceptual model, which was applied to the absolute permeability water injection experiment. It can also be observed that the frequency of the pressure spikes increases with pressure. Looking closely at the pressure data of the water injection experiments at flowrates of 2 $\mathrm{ml} / \mathrm{min}$ and $0.1 \mathrm{ml} / \mathrm{min}$, Figure 4.10 and Figure 4.11, the magnitude of the pressure fluctuations and its frequency increase with inlet pressure. The lower net stresses at higher inlet pressures causes the fracture apertures to be relatively more unstable. The changing phase structure, or the distribution of the phases in the fracture, further aggravates the instability. 


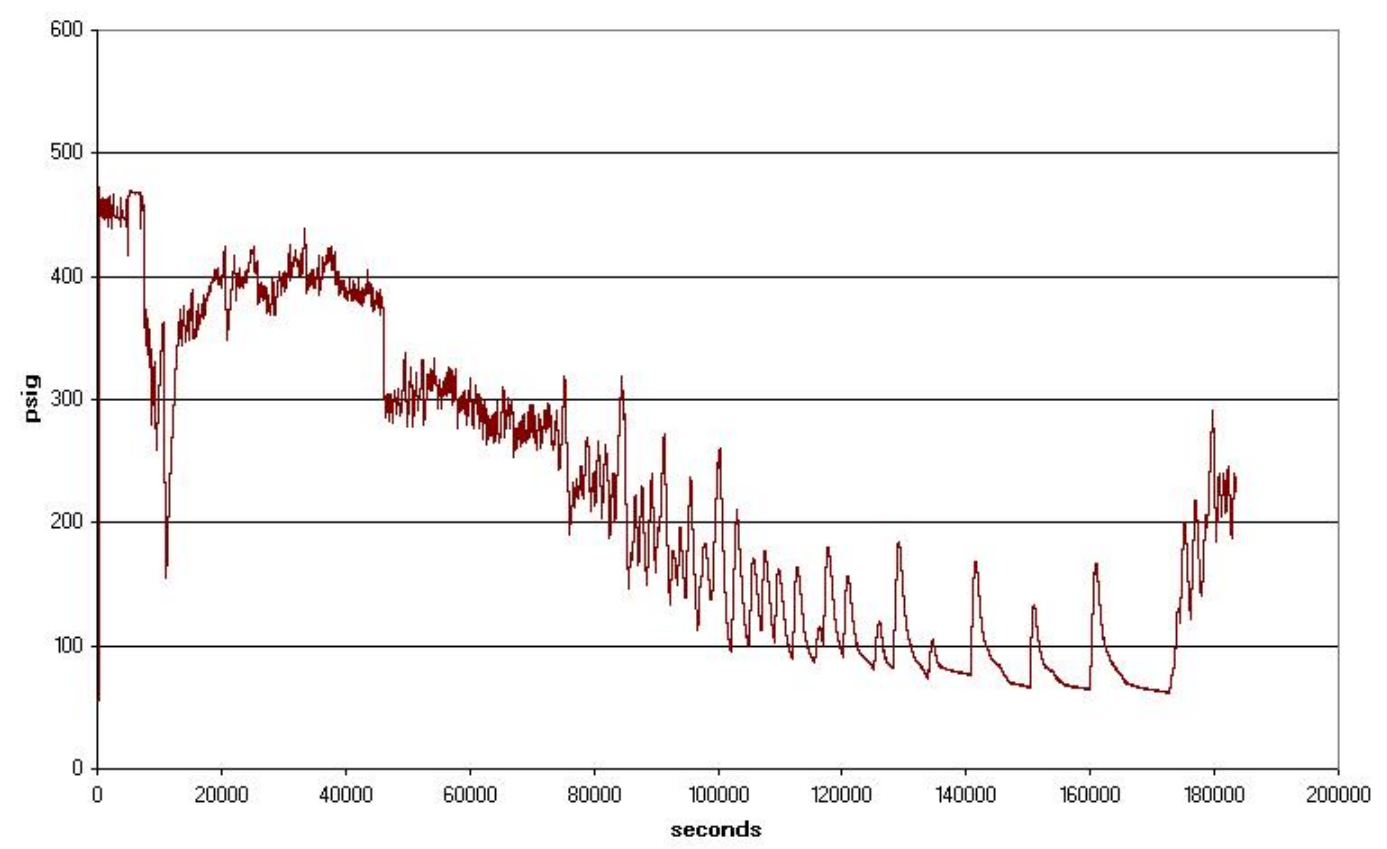

Figure 4.23: Pressure at inlet for constant flowrate nitrogen-water relative permeability experiment.

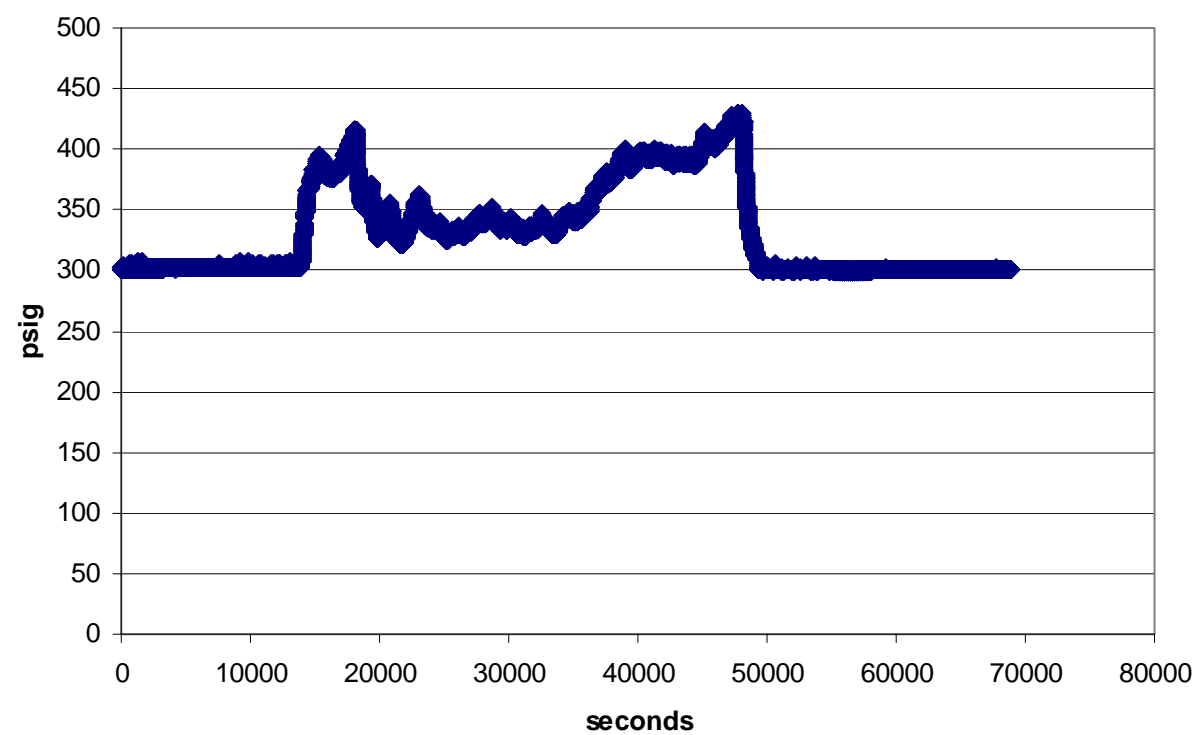

Figure 4.24: Pressure at inlet for nitrogen-water relative permeability experiment. 


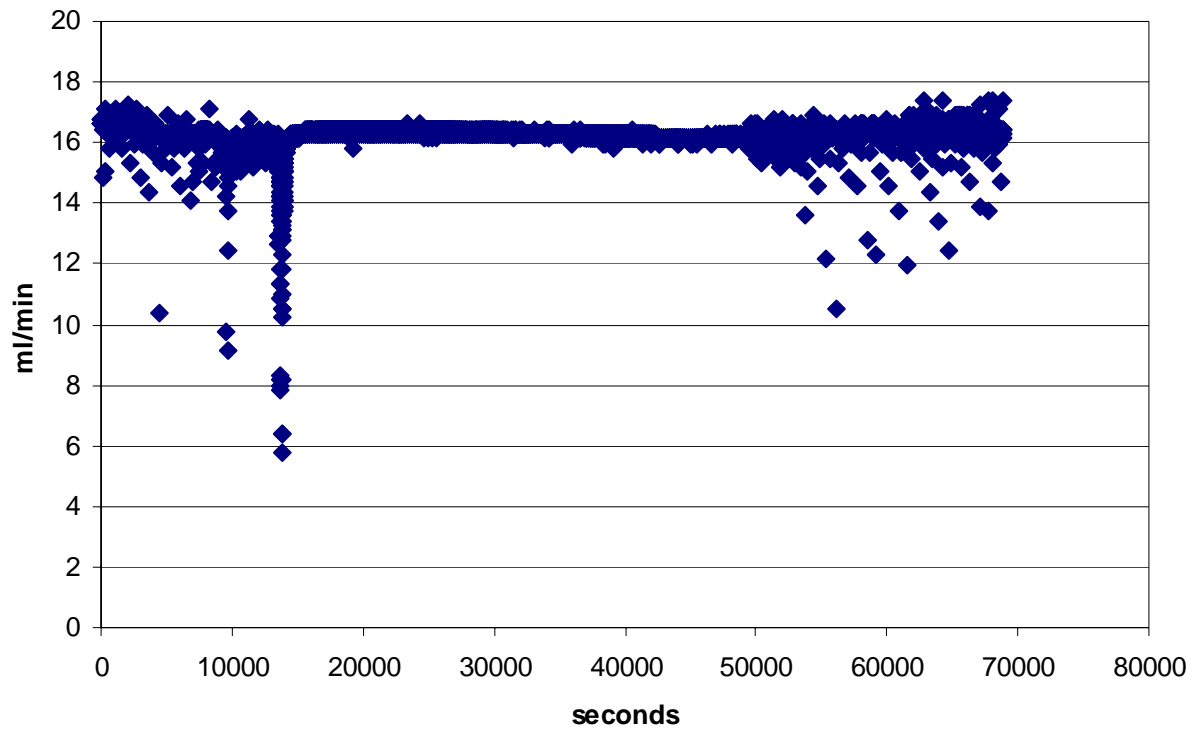

Figure 4.25: Nitrogen inlet flowrate for nitrogen-water relative permeability experiment.

The experiment shown in Figure 4.24 and Figure 4.25 was conducted at constant water flowrate. A pressure regulator controlled the nitrogen inlet pressure. Instability occurs in either the pressure or nitrogen flowrate. When the pressure is constant the nitrogen flowrate fluctuates and vice-versa. Phase interference may be the culprit. 


\section{Chapter 5}

\section{Conclusions}

The experiments conducted on The Geysers geothermal core were not all successful. However, data from this experimental study gives insights into behavior of fractures and fluid flow through these fractures that will be helpful in future research work. Basic geothermal rock properties such as irreducible saturations and porosity were determined.

1) The irreducible water saturation of The Geysers geothermal rock is approximately $15 \%$. The irreducible gas saturation obtained is around $20 \%$, but may actually be lower. Porosity of the core is $4.3 \%$.

2) The resistivity method provides acceptable estimates of average water saturation in the core. The error is within $\pm 5 \%$ compared to the values obtained by weighing the core.

3) At the endpoint saturations, the water relative permeabilities are much higher than the nitrogen gas relative permeabilities. This can be attributed to higher friction during water flows at irreducible gas saturation compared to nitrogen gas flows at irreducible water saturation. At irreducible water saturation, water will occupy small spaces in the fracture surface and reduce the surface roughness. Smoother surfaces have lower friction factors. The decrease in void volume due to the presence of water within the fractures may not be as significant as the reduction in surface roughness.

4) Flow experiments in fractures are very much linked to the rock mechanics of the fractures. Fracture aperture, fracture roughness, and fracture propagation/initiation are affected by the number of loading cycles and the net stresses applied. Eliminating these changes to the core during an experiment will be the ideal case. Nonideal situations will require quantification of these changes and incorporating the changes into the flow calculations.

5) Further work is required to obtain relative permeability values for the whole saturation range. The steady-state experimental approach encounters difficulties due to phase interference and rock fracture changes. Steady state may be reached after an impractical length of time. The unsteady-state method should be pursued. In unsteadystate experiments the challenge will be in quantifying fluid flow changes in addition to rock fracture changes. 


\section{References}

Anderson E.M., 1951, Dynamics of Faulting and Dyke Formation with Application to Britain, Hafner Publishing Company.

Archie, G.E., 1950: "Introduction to Petrophysics of Reservoir Rocks," Bulletin of the American Association of Petroleum Geologists, vol. 34, no.5, p.943-960.

Amyx, J.W., Bass, D.M.Jr., Whiting, R.L., 1988, Petroleum Reservoir Engineering, Mc-Graw Hill, Inc..

Bergosh, J.L., Lord, G.D., 1987: "New Developments in the Analysis of Cores From Naturally Fractured Reservoirs," SPE 16805.

Du, Y., Aydin, A., "Interaction of Multiple Cracks and Formation of Echelon Crack Arrays," International Journal for Numerical and Analytical Methods in Geomechanics, vol. 15, p. 205-218.

Horne, R.N., Satik, C., Mahiya, G., Li, K., Ambusso, W., Tovar, R., Wang, C., and Nassori, H.: "Steam-Water Relative Permeability," Proc. of the World Geothermal Congress 2000, Kyushu-Tohoku, Japan, May 28-June 10, 2000.

Jolly, R.J.H., Wei, L., Pine, R.J., 2000: "Stress Sensitive Fracture-Flow Modelling in Fractured Reservoirs," SPE 59042.

Jones, S.C., Roszelle, W.O., 1978: "Graphical Techniques for Determining Relative Permeability From Displacement Experiments," SPE 6045.

Jones, F.O., 1974: "A Laboratory Study of the Effects of Confining Pressure on Fracture Flow and Storage Capacity in Carbonate Rocks," SPE 4569.

Li, K., Horne, R.N., "Slip Factor in Geothermal Rocks," Stanford Geothermal program Quarterly Report(Oct-Dec 1999), p. 38-39.

Marder, M., Fineberg, J., "How Things Break", Physics Today (September 1996), American Institute of Physics. 
National Research Council Committee on Fracture Characterization and Fluid Flow, Rock Fractures and Fluid Flow: Contemporary Understanding and Applications, National Academy Press, Washington D.C., 1996, p. 1-160.

Renshaw, C.E., Pollard, D.D., "An Experimentally Verified Criterion for Propagation Across Unbounded Frictional Interfaces in Brittle, Linear Elastic Materials," Int. J. Rock Mech., Min., Sci., \& Geomech. Vol 32, no.3 p. 237-249.

Rose, W.D., 1948: "Permeability and Gas-Slippage Phenomena", $28^{\text {th }}$ Annual Mtg. Topical Committee on Production Technology. 


\section{Appendix A}

\section{A. Eclipse Simulation Code}

The flow simulation was performed by changing the properties of oil to that of nitrogen gas. Two injectors, one injecting nitrogen and the other injecting water, were placed at the left face of the core model with perforations only at the middle block. The production well was placed at the corresponding location at the right face.

Runspec Section

-- Implies the beginning of Runspec section

RUNSPEC

-- Specifies the title for the run

TITLE

2D XZ model for Imbibition

-- Gives global dimensions (number of blocks in each direction)

DIMENS

-- NX NY NZ

$20121 /$

-- List phases present in the model (oil, gas, water, diss. gas, vap. oil)

OIL

WATER

-- Specify units used in the model (metric, field, lab)

LAB

-- Specify the size of saturation and PVT tables

TABDIMS

-- NoSatTabl MaxNodesSatTab MaxFIPReg MaxSatEndpointsDepthTab

-- NoPVTTab MaxPressNodes MaxRsRvNodes

$\begin{array}{lllllll}1 & 1 & 10 & 10 & 1 & 10 & 1 /\end{array}$

-- Specify the dimensions of well data in the model

WELLDIMS

-- MaxNo MaxPerf MaxGroup MaxWell/Group

$3 \quad 50 \quad 2 \quad 2 /$

-- Specify the starting date of the simulation

START

1 'JAN' 2002 /

-- Extends the length of stack of previous search for linear solver

NSTACK

$25 /$ 
Grid Section

-- Implies the beginning of Grid section

GRID

-- Creates initial summary data for GRID, PROPS ... (needed for graphics and/or

-- 3D visualization tools, such as Floviz)

INIT

-- Creates a grid file specifying the geometry (needed for graphics and/or

-- 3D visualization tools, such as Floviz)

GRIDFILE

$1 /$

--MINPV

$--1 \mathrm{E}-10$ /

-- Specify size for all blocks in X direction (40x 100=4000 total blocks)

DX

$420 * 0.254$ /

-- Specify size for all blocks in Y direction

DY

420*5.08 /

-- Include external file created by program 'ecl_geom' containing the values

-- for tops of reservoir and size of all blocks in $\mathrm{Z}$ direction

INCLUDE

'ecl_geom.dat'

/

-- Include external file 'gsl2ecl' containing the values

-- for porosity and permeability in $\mathrm{X}$ and $\mathrm{Z}$ directions. No need to specify

-- perms in Y direction, since there is no flow in that direction (2D model)

INCLUDE

'gsl2ecl-3.out'

/

-- Include external file designed to alter the transmissibilities in $\mathrm{Z}$ direction

INCLUDE

'mud_layers4.dat'

I

-- Include external file designed to alter the transmissibilities in $\mathrm{Z}$ direction

-- for the entire reservoir.

--INCLUDE

-- 'KzKx_ratio.dat'

/

Edit Section

-- This section is optional and is not needed for this case 
-- Implies the beginning of Properties section

PROPS

-- Specify water rel perm and capillary press as a function of water saturation SWFN

-- Sw Krw Pc

$\begin{array}{lll}0.20 & 0.000 & 0.019363\end{array}$

$\begin{array}{lll}0.30 & 0.000 & 0.017427\end{array}$

$\begin{array}{lll}0.40 & 0.000 & 0.015491\end{array}$

$\begin{array}{lll}0.50 & 0.060 & 0.014523\end{array}$

$\begin{array}{lll}0.60 & 0.200 & 0.013554\end{array}$

$\begin{array}{lll}0.70 & 0.460 & 0.011618\end{array}$

0.800 .8000 .010650 /

-- Specify oil rel perm and capillary press as a function of oil saturation SOF2

-- So Kro

0.200 .000

0.300 .015

$0.40 \quad 0.050$

0.500 .110

0.600 .150

0.700 .200

$0.800 .300 /$

-- Specify properties of water phase

PVTW

-- P_reference FVF Compressibility Viscosity@Pref
291.
$1.05 \quad 0.000$
$0.325 /$

-- Specify properties of rock matrix

ROCK

-- P_reference Compressibility $291.0 \quad 0.000003 /$

-- Specify densities for all phases at surface conditions

DENSITY

-- oil wat gas

$0.001 \quad 1.0220 .001 /$

-- Specify properties of dead oil (no dissolved gas)

PVDO

-- P_oil FVF Viscosity

$\begin{array}{lll}0 & 1.0 & 0.0178\end{array}$

$\begin{array}{lll}40 & 0.4 & 0.0178\end{array}$

$\begin{array}{lll}400 & 0.3 & 0.0178\end{array}$

/

Regions Section

-- This section is optional and is not needed for this case 
-- Implies the beginning of Solution section

SOLUTION

-- Specify initial state of the reservoir

EQUIL

-- DATUM DATUM OWC OWC GOC GOC

-- depth press depth PcOW depth PcOG $\begin{array}{llllll}1000.0 & 1.5 & 1500.0 & 0.023236 & 0.0 & 0.023236 /\end{array}$

Summary Section

-- This section is optional, but needed in this case to plot line graphs

-- Implies the beginning of Summary section

SUMMARY

-- Tabulate output of summary file data

RUNSUM

--Oil Production Rate

FOPR

--Oil Production Total

FOPT

--Water Production Rate

FWPR

--Water Cut

FWCT

--Well Bottom Hole Pressures

WBHP

'P1'

'I1'

/

--Field Average Pressure

FPR

-- saturation average values

FOSAT

FWSAT

--injection rates

FOIR

FWIR

-- Request a separate file for summary output rather than part of print file SEPARATE

-- Implies the beginning of Schedule section

SCHEDULE

-- Create restart files at every report time

RPTRST

'BASIC $=2$ '

I 
-- Apply Fully Implicit solution procedure

IMPLICIT

-- Sets simulator control parameters

TUNING

--TSINIT TSMAXZ TSMINZ TSMCHP TSFMAX TSFMIN TSFCNV TFDIFF

$\begin{array}{llllllll}1 & 60 & 0.1 & 0.15 & 3.0 & 0.30 & 0.10 & 1.25 /\end{array}$

--TRGTTE TRGCNV TRGMBE TRGLCV XXXTTE XXXCNV XXXMBE XXXLCV XXXWFL

I

--NEWTMX NEWTMN LITMAX LITMIN MXWSIT MXWPIT

$\begin{array}{llllll}40 & 1 & 100 & 1 & 15 & 8 /\end{array}$

-- Specification data for vertical oil producer on the right

WELSPECS

--Name Group I J Datum Phase

'P1' 'G1' $20 \quad 1 \quad 1 * \quad$ 'OIL'/

/

-- Specification for completion of oil producing well

COMPDAT

--Name I J K1 K2 Status Sattab Trfact Diam EffKh Skin

'P1' $20 \quad 1 \quad 11 \quad 11$ 'OPEN' $1 * \quad 1 * \begin{array}{lllll}* & 0.15 & 1 * & 0.0 /\end{array}$

I

-- Control data for oil producing well

WCONPROD

--Name Status Mode "o_rate" "w_rate" "g_rate" "1_rate" "rf_rate" BHP

'P1' 'OPEN' 'BHP' $1 * \quad 1^{*} \quad 1^{*} \quad 1^{*} \quad 1^{*} 1.0 /$

I

-- Specification data for injector well on the left

WELSPECS

--Name Group I J Datum Phase

'I1' 'G2' $1 \quad 1 \quad 1 * \quad$ 'WATER' /

I

-- Specification for completion of injector well

COMPDAT

--Name I J K1 K2 Status Sattab Trfact Diam EffKh Skin

'I1' $11111 \quad 11 \quad$ 'OPEN' $1 * \quad 1 * 0.15 \quad 1 * \quad 0.0$ /

I

-- Control data for water injecting well

WCONINJ

--Name Type Status Mode "w_rate" "rf_rate" ReinjFr ReinjFlage" BHP

'I1' 'WATER' 'OPEN' 'RATE' $0.6 \quad 1 * \quad 1^{*} \quad 1^{*} 200 /$

/

-- Specification data for injector well on the left

WELSPECS 1

--Name Group I J Datum Phase 


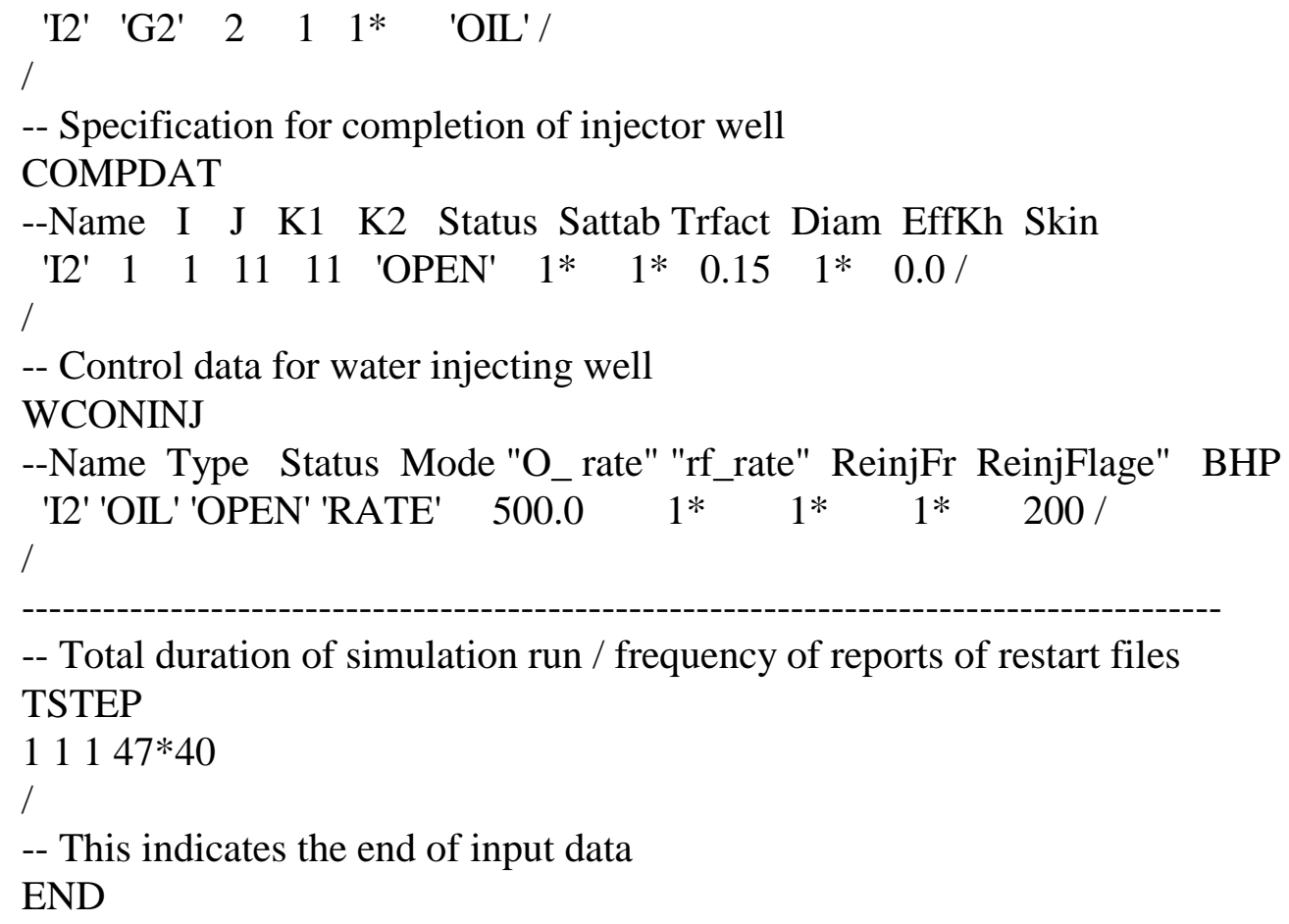




\section{Appendix B}

\section{B. Equipment Information}

\section{B.1 Water Pump}

Dynamax Model SD-200 S/N C61260

\section{B.2 Flowmeter}

Matheson Model 8170 (200 SCCM)

Digital display S/N 95285

Transducer S/N BU 9504003

\section{B.3 Flowmeter and Controller}

Matheson Model 8270 (2 SLPM)

Digital display S/N 95284

Transducer S/N AU9505010

\section{B.4 Pressure Transducer at Inlet}

Diaphragm maximum differential pressure: 800 psi

Validyne digital display S/N 116618

Validyne pressure transducer $\mathrm{S} / \mathrm{N}$

\section{B.5 Pressure Transducer at Outlet}

Diaphragm maximum differential pressure: 500 psi

Celesco digital display S/N A25409

Celesco pressure transducer S/N 23889 


\section{B.6 Balance}

Mettler PE1600 S/N D24390

Labview code shown below:

\section{B.7 Automated Data Acquisition Hardware}

National Instruments SCB 68 S/N CEAB42

National Instruments PCI 6024E S/N 10044FB

\section{B.8 Resistance Meter}

Radio Shack Multimeter S/N 22-163

\section{B.9 LabView Data Logging Code for Mettler 1600}

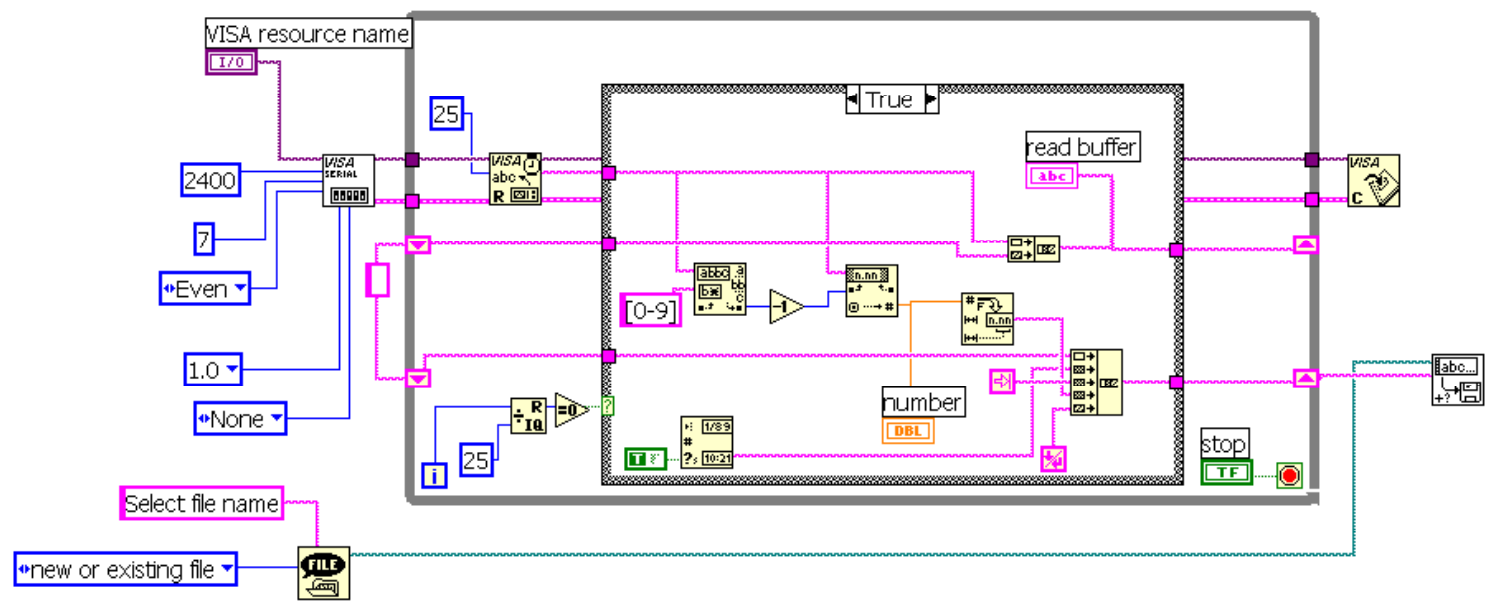




\section{B.10 LabView Data Logging Code for Pressure and Flowrate Measurements}

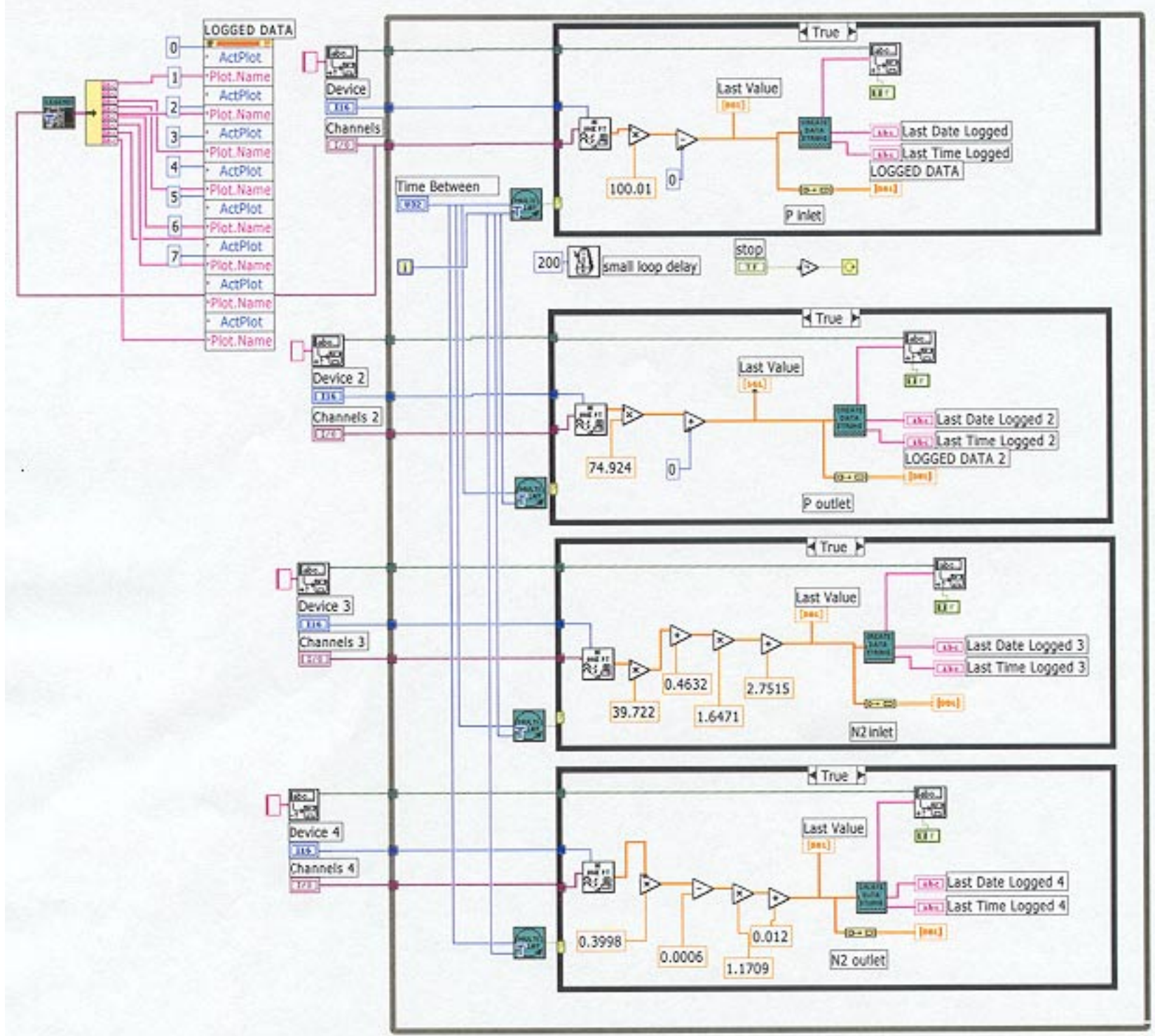


